DOI: $10.1002 /$ ((please add manuscript number))

Article type: Full Paper

\title{
Magnetic mesoporous nanocarriers for drug delivery with improved therapeutic efficacy
}

Albert Serrà, Núria Gimeno, Elvira Gómez, Margarita Mora, Maria Lluïsa Sagristà, and Elisa Vallés*

Albert Serrà, PhD Student, Grup d'Electrodeposició de Capes Primes i Nanoestructures (GECPN), Departament de Ciència de Materials i Química Física and Institut de Nanociència i Nanotecnologia (IN ${ }^{2}$ UB), Universitat de Barcelona, Martí i Franquès 1, E-08028, Barcelona, Catalonia, Spain.

Núria Gimeno, Master Student, Grup d'Electrodeposició de Capes Primes i Nanoestructures (GE-CPN), Departament de Ciència de Materials i Química Física and Institut de Nanociència i Nanotecnologia (IN ${ }^{2}$ UB), Universitat de Barcelona, Martí i Franquès 1, E-08028, Barcelona, Catalonia, Spain.

Dr. Elvira Gómez, Grup d'Electrodeposició de Capes Primes i Nanoestructures (GE-CPN), Departament de Ciència de Materials i Química Física and Institut de Nanociència i Nanotecnologia (IN $\left.{ }^{2} \mathrm{UB}\right)$, Universitat de Barcelona, Martí i Franquès 1, E-08028, Barcelona, Catalonia, Spain.

Dr. Margarita Mora, Departament de Bioquímica i Biologia Molecular, Facultat de Biologia, Universitat de Barcelona, Avinguda Diagonal, 643, E-08028, Barcelona, Catalonia, Spain.

Dr. Maria Lluïsa Sagristà, Departament de Bioquímica i Biologia Molecular, Facultat de Biologia, Universitat de Barcelona, Avinguda Diagonal, 643, E-08028, Barcelona, Catalonia, Spain.

Dr. Elisa Vallés, Grup d'Electrodeposició de Capes Primes i Nanoestructures (GE-CPN), Departament de Ciència de Materials i Química Física and Institut de Nanociència i Nanotecnologia ( IN $^{2} \mathrm{UB}$ ), Universitat de Barcelona, Martí i Franquès 1, E-08028, Barcelona, Catalonia, Spain. E-mail: e.valles@ub.edu.

Keywords: drug delivery; mesoporous magnetic carriers; nanorods; microemulsions; irinotecan (CPT-11).

Mesoporous CoNi@Au core@shell nanorods were synthesized as magnetic drug nanocarriers by electrodeposition using ionic liquid-in-aqueous microemulsions. Mesoporous nanorods present a highly effective area $\left(186 \mathrm{~m}^{2} \mathrm{~g}^{-1}\right)$ and magnetic character that allows their manipulation, concentration and retention by applying a magnetic field. The nanorods have been functionalized with thiol-poly(ethyleneglycol) molecules and molecules of Irinotecan 


\section{WILEY-VCH}

(CPT-11), a drug used in chemotherapy, were retained in both the lattice of the linked thiolpoly(ethyleneglycol) molecules and inside the interconnected nanorods pores. The nanorods' mesoporous character allowed a high drug-loading capability and magnetic behavior that allowed the drug's controlled release.

A high cellular viability of HeLa cells was obtained after their incubation with the nanorods functionalized with thiol-poly(ethyleneglycol). However, when the nanorods functioned as carriers for CPT-11, significant cell death was occurred when the HeLa cells were incubated with the functionalized, drug-loaded, nanorods. Cell death also occurred by applying an alternating magnetic field, given the effect of both the carrier's CPT-11 release and the mechanical damage of cells by the nanorods under the magnetic field effect. Our proposal to used mesoporous magnetic nanorods as drug carriers could thus dramatically reduce the amounts of the nanocarrier and the drug needed to efficiently destroy cancer cells.

\section{Introduction}

Different types of nanomaterials - polymeric micelles, dendrimers, liposomes, nanoparticles, and nanorods, among others- have been proposed as drug delivery systems (DDSs) and, in recent decades, have been studied extensively as powerful tools to improve therapeutic efficacy.

${ }^{[1]}$ More recently, intensive research has sought to design novel smart nanocarriers of drugs to control therapeutic outcomes, target modalities toward specific diseases, and minimized side effects. $^{[2]}$ The effect of the drug delivery system on the activity, localization, and tumor accumulation of different drugs has been investigated. Thus, we have already procured liposomes, micelles and other solubilizing products to carry photosensitizers for photodynamic therapy and camptothecins for chemotherapy, and their usefulness has been assessed by using healthy and cancerous cell lines, for in vitro experiments, and DBA/2 tumor bearing mice, for in vivo assays. ${ }^{[3]}$ By extension, researchers have also explored using environmentally 
responsive smart nanocarriers that can improve pharmacological efficacy due to physicochemical changes that occur during exposure to external stimuli. These stimuli, which can be combined to further enhance pharmacologic activity, include light, temperature, ultrasound, magnetic field, electrical field, and chemical signals such as $\mathrm{pH}$, ionic strength, redox potential, and enzymatic activities. ${ }^{[4]}$ Using nanocarriers combined with external or internal stimuli improve the control of drug delivery over that of traditional release systems in vivo (i.e., passive delivery programed prior to implantation) that cannot be modified when the needs of therapeutic change. As such, nanomaterials have the potential to revolutionize the diagnostic and therapy of cancer, one of the world's most devastating diseases. They could be of particular use with colorectal cancer (CRC), the third most common cause of cancer deaths among both men and women in the United States and Europe, as well as the second most common lethal cancer overall. ${ }^{[5]}$

Current cancer treatments involve surgical intervention, radiation, and chemotherapy, typically accompanied by toxic side effects that limit the drug dosage that can be given to a patient, since not all the tumor tissue can be exposed to a lethal dose of the drug. ${ }^{[6]}$ In the last decade, several new cytotoxic agents have been explored for colorectal cancer treatment. Among them, irinotecan (CPT-11), a water-soluble semisynthetic camptothecin derivative of the Topoisomerase I family of interactive compounds, is used in current chemotherapy protocols for a range of tumor diseases. ${ }^{[7]}$ Such findings are important, because using nanostructured materials as carriers can significantly improve the pharmacological properties of drugs, by encouraging the drug's accumulation in the target tissue. Their unique properties can also enhance therapeutic efficacy with the application of specific external stimuli, which as triggers in drug delivery systems enable a spatially, temporally, or even spatiotemporally controlled release that can play a major role in sustained release systems. ${ }^{[8]}$

At the same time, designing carriers capable of selectively releasing their payloads at target sites in the body has special relevance in drug delivery systems. Special attention was given to 


\section{WILEY-VCH}

receptor mediated delivery systems, in particular, those targeted to folate receptor that has been shown to increase the uptake of the entrapped drugs by folate receptor positive cells. ${ }^{[9]}$ In that context, magnetic nanocarriers represent a promising opportunity because they can be concentrated and kept with an external field. ${ }^{[10]}$ In recent years, increased efforts have been put toward developing magnetic nanomaterials for nanobiomagnetic applications, including the use of magnetic resonance imaging contrast agents, targeted drug delivery, bioseparation, and magnetically induced hyperthermia. ${ }^{[10,11]}$ Those applications are possible because magnetic nanomaterials, especially magnetic nanoparticles, can be remotely manipulated by magnetic fields. Crucial to such biological applications is a quasi-zero magnetization remanent state, which prevents the magnetic agglomeration of nanomaterials by virtue of their interaction with remanent moments, which in turn stabilizes the nanomaterial's suspension. ${ }^{[12]}$ By extension, surface functionalization could be used to minimize their aggregation. ${ }^{[13]}$ Via hyperthermia or mechanical destruction of cells, magnetic nanomaterials can furthermore be heated or rotated, respectively, under alternating fields during cancer therapy. ${ }^{[14]}$ Altogether, the integration of magnetic materials with biological molecules into chemotherapy can generate smart hybrid materials with promising advanced properties.

Herein, we propose the synthesis of magnetic mesoporous CoNi@ Au core@shell nanorods, $100 \mathrm{~nm}$ in diameter and approximately $2 \mu \mathrm{m}$ in long, by electrodeposition using ionic liquidin-aqueous solution (IL/W) microemulsions that can be used as smart drug nanocarriers. The objective of this study was to obtain intelligent drug nanocarriers that met four criteria: First, nanorod shape and high density of interconnected mesopores needed to offer a surface area conducive to supporting high quantities of drugs. Second, magnetic actuation needed to radically enhance therapeutic efficacy by allowing easy manipulation, magnetic targeting, mechanical destruction and better control of drug release by way of high saturation magnetization $\left(\mathbf{M}_{\mathrm{s}}\right)$ and low remanence $\left(\mathbf{M}_{\mathrm{r}}\right)$. Third, low cytotoxic effects and high biocompatibility were needed to achieve high cellular viability in the presence of carriers. 


\section{WILEY-VCH}

Fourth, the nanocarriers needed to demonstrate ease of functionalization, retention, and release of drugs. To test the applicability of nanocarriers, the CPT-11 drug was analyzed for its retention and posterior release from the nanocarrier, in magnetic stirring and non-stirring conditions. The high surface area and the high drug-loading capability of the CoNi@Au mesoporous nanorods, the controlled release of the drug by means of a magnetic field, the uptake of the nanorods in the interior of the test HeLa cells and the cellular death of the test cells by both the release of the carcinogenic drug and the mechanical destruction of the cells by the rotating magnetic field applied make the new nanostructures excellent candidates for increased therapeutic efficiency. In sum, the findings of our study could contribute to reducing the amount of drug nanocarriers in a therapeutical treatment and thus bringing about more efficient carcinogenic cell destruction.

\section{Results and Discussion}

This paper presents the possibility of using magnetic compact or mesoporous nanorods as nanocarriers for drugs. In biomedical applications, nanorods offer advantages over other magnetic nanostructures, including higher magnetic moments per unit of volume and larger surface-to-volume ratios, especially in the case of mesoporous rods. Although $\mathrm{Fe}$ and $\mathrm{Ni}$ nanorods have been proposed for some biomedical applications, ${ }^{[15]}$ we propose using CoNi@Au nanorods, largely because they present high $\mathrm{M}_{\mathrm{s}}$ and improved chemical stability. ${ }^{[13 b, 16]}$ In doing so, we acknowledge the well-known fact that the toxicity of such materials, dependent on their contents in biological media, is extremely low and can be eliminated from the body in a relatively short time. ${ }^{[10]}$ Moreover, the formation of a gold shell over the entire surface of the nanorods prevents the dissolution of the metals, while the functionalization of core@shell nanorods with long PEG molecules makes them hydrophilic and minimizes their aggregation. Ultimately, we propose the synthesis of new nanorods as drug carriers for 


\section{WILEY-VCH}

pharmacologic treatments in cancer therapy. Along with the functionalization of drug-loaded nanorods, using these devices would make it possible to deliver specific drugs to tumor tissues by way of a magnetic field, which would dramatically increase the benefits of treatment

\subsection{Nano-carriers Fabrication and Characterization}

Electrodeposition in potentiostatic conditions was used as a synthetic route for preparing mesoporous and compact nanorods, using microemulsions with ionic liquids and aqueous solutions as electrochemical media, respectively. ${ }^{[17]}$ After synthesis and washing, the magnetic nanorods were immersed in a gold salt solution to form a gold shell by galvanic displacement under ultrasound stirring. Synthesis is illustrated in Figure 1. We combined the use of a soft template (i.e., microemulsion) for pore definition and a hard template (i.e., polycarbonate membranes) for nanorods growth in order to control of the length, diameter and pore size by way of controlling the deposition time, hard template type, and the microemulsion structure, respectively. Notably, this method affords mesoporous or compact nanorods of numerous metallic and compositions, all by controlling the composition of the aqueous solution and selecting the deposition potential.

Earlier, to electrodeposit nanorods inside the polycarbonate membranes, we analyzed the electrodeposition process in the three electrochemical media: microemulsion (i.e., to obtain mesoporous nanorods), aqueous solution (i.e., to obtain compact nanorods) and an aqueoussurfactant mixture (i.e., to understand the surfactant effect). It is possible electrodeposit CoNi from the three types of electrochemical media (Supporting Information) inside the nanochannels of polycarbonate (PC) membranes, which also allows the selection of the most adequate deposition potential in order to ensure the desired composition and deposition rate. The voltammetric study (see Supporting Information) of the CoNi system reveals a different voltammetric profile in presence of either the microemulsion or aqueous-surfactant mixture in respect to the classical profile in the aqueous solution. The first reduction peak occurred at 
around $-0.6 \mathrm{~V}$, assigned to the initial nickel deposition, followed by a primary reduction from $-0.8 \mathrm{~V}$, assigned to the simultaneous codeposition of nickel and cobalt and a single oxidation peak, corresponding to the alloy oxidation in the anodic scan. However, with microemulsion, a lower $j / E$ slope occurred due to the lower deposition rate in the more viscous microemulsion medium than in the aqueous solution. A similar $Q_{\mathrm{ox}} / Q_{\text {red }}$ ratio in the voltammetric process reflects the dismal participation of hydrogen evolution in both media.

The viscosity, surface tension and conductivity (Table 2S) of the three electrodeposition media were also measured to corroborate the possibility of filling the nanochannels of the PC membrane. From the voltammetric study, a deposition potential of $-1,000 \mathrm{mV}$ for the different electrochemical media with a relatively high deposition rate was selected, thereby ensuring comparable homogeneous growth comparable in three different systems in terms of efficiencies and alloy composition (Table 1S).

Chronoamperometric curves of synthesis (Figure 2Sa) in stationary conditions evolved to quasi stationary values, which reflect a constant growth regime. The deposition rate was greater with compact nanorods (i.e., aqueous solution) due to the lower viscosity of the medium. Nanorods were released from the PC membrane and, after thorough washing, immersed in a gold solution, which resulting in the formation of a thin gold shell due to galvanic displacement. As scanning electron microscopy showed (Figure 2Sb and c) nanorods maintained their integrity after the formation of the Au shell, and nanorods of similar lengths (Figure 2Sc) and diameter emerged in both electrochemical media. Both type of nanorods exhibit similar composition before Au shell formation, which demonstrates that using electrodeposition with selected baths and conditions allows the preparation of CoNi nanorods with modulated composition. However, as Table 1 depicts, mesoporous nanorods contained a significantly more Au after the galvanic displacement, as could be expected due to their significantly greater area. 


\section{WILEY-VCH}

We characterized the morphology of the prepared nanorods by way of transmission electron microscopy (Figure 2), representative images of which reveal significant differences according to preparation approach. Nanorods obtained in aqueous solution displayed compact morphology and a diameter of $104 \pm 9 \mathrm{~nm}$, dispersion likely due to the insufficient uniformity of nanochannels in the PC membrane (Figure 2a). By contrast, IL/W microemulsions yielded mesoporous nanorods with a high density of well-defined nonspherical mesopores over the entire area, even at the inner part of the wires that formed an ordered, interconnected pore network with easy accessibility (Figure $2 \mathbf{b}$ ). The diameter of the mesoporous nanorods was of $107 \pm 12$ and the size of the mesopores approximately 2-4 $\mathrm{nm}$. The average size of mesopores was coherent since ionic liquid droplets (hydrodynamic diameter $=12.4 \mathrm{~nm}$; polydispersity index $=0.08$ ) were slightly larger. This result is unsurprising, for pores are defined by the size of ionic liquid droplets, which should be smaller than the hydrodynamic diameter determined by DLS. X-ray diffractograms (Figure 4S) of both compact and mesoporous CoNi@Au nanorods show several peaks assigned to gold, given its presence in the shell and its significant diffracting response. Several peaks corresponding to the CoNi core were observed at 41.6, 47.5, $76.1,92.5$, and $98.7^{\circ} 2 \theta$, which respectively correspond to the (100), (101), (110), (112), and (004) peaks of a Co hexagonal close-packed (hcp) crystalline phase, albeit slightly distorted due to the presence of $\mathrm{Ni}$ in the alloy. Other peaks of the Co hcp phase can be masked by gold's diffraction peaks. A low proportion of a CoNi face-centered cubic (fcc) phase was detected at a peak of $51.6^{\circ} 2 \theta$. This primarily hep crystalline structure has previously been obtained for CoNi films and nanorods. ${ }^{[18]}$ Moreover, the selected area electron diffraction patterns of the synthesized nanorods (Figure 4Sa, b) can be also indexed as the (002), (101), (110) and (100) orientations of the distorted Co hexagonal close-packed structure.

To use the nanorods synthesized as drug carriers, it is important to know the area that can effectively host pharmaceutical compounds. After covering them with the gold shell and recording the voltammetric response of the $\mathrm{CoNi@Au} \mathrm{nanorods} \mathrm{in} \mathrm{sulfuric} \mathrm{acid,} \mathrm{we} \mathrm{therefore}$ 


\section{WILEY-VCH}

calculated the electrochemical surface area of each nanorod type. The charge associated with the reduction of gold oxide (Figure $\mathbf{2 c}$ ) was proportional to the highly active area of the gold surface. ${ }^{[19]}$ We were also to confirm the complete formation of the Au shell over the entire area of both structures, since nanorods supported on a glassy carbon (GC) electrode were immersed in a $\mathrm{H}_{2} \mathrm{SO}_{4} 0.5 \mathrm{M}$ solutions for 5 minutes, after which a successive cyclic voltammetry was performed. CoNi nanorods were etched and dissolved when unprotected by the Au shell after 5-min immersion in acidic media, which we verified by cyclic voltammetry that showed the response of the bare GC electrode. When the gold layer completely covered the nanorod, CoNi@ $\mathrm{Au}$ was netter protected, even in $\mathrm{H}_{2} \mathrm{SO}_{4}$.

In sum, for both compact and mesoporous nanorods, the typical profile of gold in sulfuric solution was obtained (Figure 2c), even despite a high number of scans (> 20). The voltammetric technique therefore allowed us to determine the immersion time that assures a complete gold layer on the surface of the nanorods. The stability of the CoNi@ Au nanorods in the aggressive medium supposes their stability in a less aggressive (i.e., cellular) medium. The electrochemical surface area for both compact and mesoporous nanorods was 19 and $186 \mathrm{~m}^{2} \mathrm{~g}^{-}$ ${ }^{1}$, respectively, while their Au shell thickness $(S T)$ was 0.7 and $0.1 \mathrm{~nm}$, also respectively (Table 1). The Au shell thickness can be calculated from the ECSA values as follows(Eq.1):

$$
S T=\frac{V_{A u}}{S_{A u}}=\frac{\left(\frac{m_{N R} \cdot P_{A u}}{\rho_{A u}}\right)}{E C S A \cdot m_{N R}}=\frac{P_{A u}}{E C S A \cdot \rho_{A u}}
$$

where $V_{A u}$ is the volume of Au shell, $S_{A u}$ is the surface of Au shell, $m_{N R}$ is the mass of one nanorod, $P_{A u}\left(g_{A u} / g_{C o N i @ A u}\right)$ is the weight percentage of Au of one nanorod, ECSA $\left(\mathrm{m}^{2} / g_{\text {CoNi@Au }}\right)$ is the mass-normalized electrochemical surface area and $\rho_{A u}\left(g_{A u} / \mathrm{cm}^{3}\right)$ is the density of gold.

\subsection{Nanorods functionalization and drug loading, magnetic properties and drug Release}




\section{WILEY-VCH}

\subsubsection{Functionalization and drug loading.}

Following the Au shell formation, the CoNi@Au nanorods were functionalized with HS-PEG or HS-PEG + CPT-11. First, the CoNi@Au-SH-PEG nanorods were used to detect the functionalization, whereas nanorods containing HS-PEG + CPT-11 were used to study the retention and release of the drug. Second, the CoNi@Au-SH-PEG nanorods were used to examine nanorods toxicity using HeLa cells, whereas the CoNi@Au-SH-PEG nanorods loaded with CPT-11 were used to investigate drug cytotoxicity delivered to HeLa cells via nanorod carriers. Lastly, CoNi@Au-SH-PEG nanorods, both with and without CPT-11, were also used to gauge HeLa cells' uptake of nanorods by way of confocal microscopy.

Functionalization was performed by immersion the nanorods in a solution of the nonpolar organic thiol with or without the selected drug in stirring conditions ( $800 \mathrm{rpm}$ ) for $48 \mathrm{~h}$, chiefly to form a highly stable organic monolayer due to the strong gold-sulfur bonding. Figure 3a portrays the overall strategy of the functionalization with HS-PEG + CPT-11 (i.e., drug-loading scheme). The HS-PEG monolayer rendered the nanorod surface hydrophilic and minimizes the aggregation of the magnetic nanorods favoring its interaction with cells, as well as incorporated and retained CPT-11 inside the polymeric network and inside the interconnected pore network in mesoporous structures. We hoped that the retention of the drug in the organic network would labile enough to make release moderately easy. Following the functionalization, the nonsedimentation of the nanorods was observed for 7 days, which signifies significant improvement in the stability of the suspension fundamental for biomedical applications. The procedure also afforded the modification of the surface properties of the nanorods - for example, in terms of surface charge and specific recognition of nanorods.

The formation and integrity of organic adsorbed layers onto the gold electrode was tested using voltammetric experiments, ${ }^{[13 a]}$ in which a close-packed layer of HS-PEG on the nanorod surface should hinder, if not block, the electrochemical superficial oxidation of the gold or the 


\section{WILEY-VCH}

reduction of gold oxide, as well as the oxidation or reduction of species in solution on the nanorod surface. Therefore, to verify nanorod functionalization with HS-PEG, we performed electrochemical probe experiments by recording cyclic voltammetries of the $\mathrm{Fe}$ (II)/Fe (III) system in both CoNi@Au and CoNi@Au-SH-PEG NRs (Figure 3b). To that end, a drop of nanorod suspension was placed on the surface of a GC substrate and dried to obtain each GCnanorod electrode. Figure 3b shows the typical reversible couple of the Fe (II)/Fe(III) system for the nonfunctionalized CoNi@Au nanorods. For the same amount of nanorods on the GC surface, the detected current was significantly greater for mesoporous nanorods, which corresponds to the far greater effective area. The presence of the PEG layer in the CoNi@AuSH-PEG nanorods caused a blocking effect of the surface of both mesoporous and compact CoNi@Au nanorods, thereby prompting a drastic decrease of the detected current. The electrochemical probe then allowed us to detect the functionalization of the nanorods with a HS-PEG layer. The faradaic Fe (II)/Fe (III) processes were strained with HS-PEG was on the nanorods, though the electrochemical processes were not entirely hindered, which reveals that some mass transport of the Fe (II)/Fe (III) redox species occurs in the presence of the HS-PEG layer to the nanorods surface. This finding is important because the mass transport of the drug to the entire bulk should also be possible for drug release.

\subsubsection{Magnetic properties of the functionalized nanorods.}

The magnetic properties of the CoNi@Au nanorods, both compact and mesoporous, were analyzed before and after their functionalization with HS-PEG molecules. Figure 4Sc shows the normalized $\mathrm{M} / \mathrm{M}_{\mathrm{S}}$ (M: magnetization) curves for the four types of nanorod. The response of the functionalized nanorods was highly similar to that of the nonfunctionalized ones, which indicates that the presence of HS-PEG molecules does not preclude the manipulation of the magnetic nanorods. Indeed, they can be easily retained or targeted by applying a magnetic field. 


\section{WILEY-VCH}

Compact CoNi@Au nanorods presented a soft-magnetic behavior, with a $\mathrm{M}_{\mathrm{r}} / \mathrm{M}_{\mathrm{s}}=0.3\left(\mathrm{M}_{\mathrm{r}}\right.$ : remanence) and a coercivity $\mathrm{H}_{\mathrm{c}}=230$ Oe. Mesoporous CoNi@ Au nanorods tended to exhibit superparamagnetic behavior, with low values for both remanence $\left(\mathrm{M}_{\mathrm{r}} / \mathrm{M}_{\mathrm{S}}=0.1\right)$ and coercivity $\left(\mathrm{H}_{\mathrm{C}}=50 \mathrm{Oe}\right)$, a fact that favors their rapid response under an applied magnetic field and decreases their tendency to aggregate. In fact, both functionalized and nonfunctionalized mesoporous nanorods were easily maintained in suspension due to their magnetic properties and the low mass-per-volume of the unit.

When a suspension of nanorods was subjected to the action of a rotating magnetic field, the nanorods readily commenced a circular motion, with a rotational speed according to the applied magnetic field. Therefore, the magnetic character of the synthesized nanorods allowed handling during washing, targeting and accumulation in a defined target site, and movement in suspension.

\subsubsection{Drug release.}

The In vitro drug retention and release were studied via spectrofluorimetric assay after the incubating both the compact and mesoporous nanorods with PEG (CoNi@Au-SH-PEG) and CPT-11. The comparison of the fluorescence of the CPT-11 in a $10 \mathrm{mM}$ lactate buffered $(\mathrm{pH}$ 4.4) solution before and after its incubation with the nanorods and the HS-PEG (i.e., nanorod cofunctionalization) demonstrated drug retention in the lattice of the HS-PEG molecules, for compact nanorods, and also in the interior of the pores, for mesoporous nanorods. The maximum yield of CPT-11 retention in mesoporous nanorods was of 76\%, a significantly higher value than the 36\% retention efficiency of the compact CoNi@Au-HS-PEG nanorods. Mesoporous nanorods exhibited an increased ability to accumulate the drug and thus higher retention efficiency. That result could be the expected, given their exceptionally high pore volume, which can accommodate the drug. 


\section{WILEY-VCH}

The magnetic properties of the synthesized and functionalized nanorods were studied regarding the CPT-11 release in static conditions, as well as under the influence of an external rotatory magnetic field $(20 \mathrm{~Hz})$. The aim of these assays was to assess whether the drug release was magnetic-dependent and thus the rate of release controllable. Figure 4a shows a diagram of the different release conditions considered in our work. Figure $\mathbf{4 b - e}$ show the release profiles of CPT-11 trapped in CoNi@Au-SH-PEG nanorods. Irinotecan-loaded nanorods were first washed 3 times with $1 \mathrm{~mL}$ of the lactate-buffered medium and placed in $1 \mathrm{~mL}$ of the same buffer, after which the release of the drug was measured for $25 \mathrm{~h}$. As Figure 4 shows, the release profiles of CPT-11 from compact and mesoporous nanorods, expressed as the percentage of the drug released, in static conditions and under the action of an external rotatory magnetic field, were highly similar. However, in absolute terms, significantly more CPT-11 was released with mesoporous structures, as expected, due to its superior load capability. Therefore, by using the mesoporous nanorods, the amount of nanocarriers needed to deliver the same amount of drug can be significantly reduced. Moreover, the magnetic-dependent release of the drug allows the modulation and control of its release rate. As such, the increased efficiency of drug release coupled with the possibility of the remote manipulation of the nanorods, by applying direct magnetic fields, and their rotational manipulation, by applying rotating fields, underscores mesoporous and compact nanorods as promising nanocarrier for cancer therapy. Magnetic nanorods can be considered smart nanocarriers because they have been engineered to provide a vast array of properties, including the ability to respond to the externally applied stimuli.

\subsubsection{Cytotoxic activity of CPT-11 loaded CoNi@Au-SH-PEG NRs.}

The effectiveness of CPT-11-loaded CoNi@Au-SH-PEG nanorods was assessed and compared with that of the carrier (i.e., CoNi@Au-SH-PEG nanorods) by using the HeLa cell line. The 


\section{WILEY-VCH}

survival of the cells, incubated for $24 \mathrm{~h}$ with a fixed amount of CPT-11 $(0.027$ and $0.080 \mu \mathrm{mol}$ of CPT-11for $20 \mu \mathrm{g} \mathrm{mL}^{-1}$ of compact and mesoporous nanorods, respectively), was evaluated $24 \mathrm{~h}$ after CPT-11 was removed from the culture medium. HeLa cells were incubated in the same conditions with empty CoNi@Au-SH-PEG nanorods, largely to study the toxicity effect of the carrier. The toxicity studies carried out with both carriers (Figure 5Sa and b) showed that HeLa cells viability was greater than $90 \%$, after incubation with empty compact and mesoporous CoNi@Au-SH-PEG nanorods, up to a concentration of 300 and $350 \mu \mathrm{g}$ nanorods $\mathrm{mL}^{-1}$, respectively. From these results we chose a concentration of $20 \mu \mathrm{g}$ nanorods $\mathrm{mL}^{-1}$ to study the toxicity of CPT-11 trapped in the nanorods.

The cytotoxic effect of drug- loaded CoNi@Au-SH-PEG nanorods (Figure 5) was a function of the type of nanorod, either compact or mesoporous, and of the application, or not, of an external rotatory magnetic field. Cells were incubated $24 \mathrm{~h}$ with empty and CPT-11 loaded CoNi@Au-SH-PEG nanorods, and cell survival was evaluated by the tetrazolium dye (MTT) colorimetric assay $24 \mathrm{~h}$ after nanorod removal.

When using empty nanorods, cell survival was greater than $90 \%$ in silent $(0 \mathrm{~Hz})$ conditions, whereas the application of an external rotatory magnetic field $(20 \mathrm{~Hz})$ for 30 min caused a $44 \%$ and a $37 \%$ decrease in cell survival for compact and mesoporous nanorods, respectively. Cell death in the absence of CPT-11 when applied in an external rotating magnetic field could be attributed to a possible localized heating or a rotation of the nanorods inside the cells.

The incubation of HeLa cells with irinotecan-loaded compact and mesoporous CoNi@ Au-SHPEG nanorods in silent conditions $(0 \mathrm{~Hz})$ prompted $15.4 \%$ and $37.5 \%$ of cell death, respectively. This result was consistent with the amount of CPT-11 released in the absence of magnetic field from a same amount of compact $(0.01 \mu \mathrm{mol}$ CPT-11 per $20 \mu \mathrm{g}$ nanorods $)$ or mesoporous $(0.033 \mu \mathrm{mol}$ CPT-11 per $20 \mu \mathrm{g}$ nanorods $)$ nanorods. 


\section{WILEY-VCH}

When the external rotatory magnetic field $(20 \mathrm{~Hz})$ was applied, after incubating the HeLa cells with the same amount of nanorods in the medium of that used in the absence of the magnetic field, a significant increase of cell death was observed in both cases. In those conditions, cell death was of $52.8 \%$ and $83.7 \%$ when HeLa cells were incubated with CPT-11 loaded in compact or mesoporous CoNi@Au-SH-PEG nanorods, respectively. Such increased cell death can be attributed to the sum of two factors: the largest release of CPT-11 when the magnetic field was applied $(0.027 \mu \mathrm{mol}$ CPT-11 per $20 \mu \mathrm{g}$ compact nanorods and $0.080 \mu \mathrm{mol}$ CPT-11 per $20 \mu \mathrm{g}$ mesoporous nanorods) and the mechanical damage of cells due to the rotation of the nanorods inside the cells under the magnetic field effect.

When these results are compared with those obtained when CPT-11 was administered in a liposomal form, it has been shown that both liposomes and CoNi@ Au-SH-PEG nanorods have excellent ability to incorporate the drug or to release it under specific stimuli: hyperthermia for thermosensitive liposomes or a magnetic field for CoNi@Au-SH-PEG nanorods. ${ }^{[3 b]}$ However, based on results from this study, mesoporous CoNi@Au-SH-PEG nanorods significantly improve the therapeutic effectiveness of irinotecan for anticancer therapy, compared to that of liposomes and other mesoporous structures, including lipid-coated mesoporous silica nanoparticles. ${ }^{[20]}$ That benefit derives from magnetic actuation, which radically enhances killing efficiency and provides easy manipulation, magnetic targeting, and better control of the drug release rate. We can hypothesize that mesoporous CoNi@ Au-SH-PEG nanorods therefore constitute an interesting alternative to other more usual nanocarriers, like liposomes, to deliver different drugs.

\subsubsection{Nanorods uptake by HeLa cells.}

CellTracker $^{\mathrm{TM}}$ 5-chloromethylfluorescein diacetate (CMFDA) was used to demonstrate nanorod internalization by HeLa cells. CMFDA is a fluorescent chloromethyl derivative that 
freely diffuses through the membranes of live cells. Once inside the cells, these mildly thiolreactive probes undergo what is thought to be a glutathion S-transferase-mediated reaction, in order to produce membrane-impermeable glutathion fluorescent dye adducts. A wide variety of applications were indicated for these dyes, including cell tracking in mixed cultures, long-term viability assays, and measuring cellular glutathione content using flow cytometry or the labelling of live cells. ${ }^{[21]}$

The green probe CMFDA stained the entire HeLa cells body, shown in green in Figure 6, which also shows nanorods, in red, that were visualized by reflection. The images show that HeLa cells internalize both compact and mesoporous CoNi@Au-SH-PEG nanorods, though that some nanorods remain extracellular.

The videos supplied (see Supporting Information) show the 3-dimensional reconstruction of alive HeLa cells with compact (Video 6S) and mesoporous (Video 7S) nanorods in their cytoplasm.

\section{Conclusion}

Electrochemical synthesis allowed us to prepare CoNi@Au-SH-PEG nanorods that demonstrated promise as magnetic nanocarriers for therapeutic molecules. Using aqueous solution allowed us to prepare compact, short ( $<2$ microns) magnetic nanorods, whereas using ionic liquid-in-aqueous solution microemulsion allowed us to prepare mesoporous nanorods of similar dimensions and composition. The formation of a gold layer covering all of the nanorods, both compact and mesoporous, allowed their functionalization with a long HS-PEG molecule, which conferred hydrophilic character to the nanorods, favored their maintenance in suspension during several days by decreasing their aggregation, allowed them to retain the selected drug (i.e., CPT-11), and allowed their gradual release. The mesoporous CoNi@Au-HS-PEG nanorods present advantages respect to the compact ones because they allow higher loading of 
drug in the interior of the pores, a higher loading of drug retained in more HS-PEG molecules adsorbed on the nanorods with higher area/volume, easy magnetic manipulation due to their specific magnetic properties, a lesser tendency toward sedimentation due to their lower mass, a lesser toxicity of carriers, and greater cell death efficiency with fewer carriers. The magnetic character of the mesoporous nanorods moreover favored magnetic manipulation, magnetic targeting, and accumulation, as well as the mechanical death of cellules accompanying the death produced by the drug.

\section{Experimental Section}

Electrochemical media: The electrochemical media used to study the deposition process and to prepare nanorods were (i) an aqueous solution (W) of $0.2 \mathrm{M} \mathrm{CoCl}_{2} \cdot 6 \mathrm{H}_{2} \mathrm{O}($ Carlo Erba $>98.0 \%)+0.9$ $\mathrm{M} \mathrm{NiCl}_{2}($ Panreac, $>98 \%)+30 \mathrm{~g} \mathrm{~L}^{-1} \mathrm{H}_{3} \mathrm{BO}_{3}$ (Merck, 99.8\%) + $0.7 \mathrm{~g} \mathrm{~L}^{-1}$ saccharin (Merck, > 98\%); (ii) an $\mathrm{W}+$ surfactant mixture $(\mathrm{W}+\mathrm{S})$ of 84.9 wt. $\%$ of $\mathrm{W}+15.1$ wt. \% of p-octyl poly(ethylene glycol) phenyl ether a.k.a. Triton X-100 (S) (Acros Organics, $98 \%$ ); and (iii) ionic liquid-in-water (IL/W) microemulsions, prepared by mixing W, S and 1-butyl-3-methylimidazolium hexafluorophosphate a.k.a. bmimPF $_{6}\left(\mathrm{C}_{8} \mathrm{H}_{15} \mathrm{~F}_{6} \mathrm{~N}_{2} \mathrm{P}\right.$, Solvionic, $\left.99 \%\right)$ (IL) in proportions based on the literature (15.1 wt. \% of $\mathrm{S}$, 1.1 wt. $\%$ of IL and $83.8 \%$ of W). ${ }^{[19]}$ The mixture was sonicated for 5 min under argon bubbling, which prompted transparent stable microemulsions. Droplet size and the polydispersity index of microemulsions were analyzed by dynamic light scattering (DLS) with Zetasizer Nano ZS (Malvern Instruments).

Electrochemical synthesis and characterization: Electrochemical experiments were carried out using a microcomputer-controlled potentiostat/galvanostat Autolab with PGSTAT30 equipment and GPES software. As shown in the Supporting Information, the voltammetric study to find the optimum range of working potentials in aqueous $(\mathrm{W})$, aqueous solution + surfactant $(\mathrm{W}+\mathrm{S})$ and ionic liquid-inwater (IL/W) microemulsions systems was performed at room temperature $\left(25^{\circ} \mathrm{C}\right)$, using a 3 -electrode electrochemical system. Si / Ti $(15 \mathrm{~nm}) / \mathrm{Au}(100 \mathrm{~nm})$ substrates $\left(0.5 \times 0.5 \mathrm{~cm}^{2}\right)$, Pt spiral, and Ag / 


\section{WILEY-VCH}

$\mathrm{AgCl} / 3 \mathrm{M} \mathrm{KCl}$ were used as working, counter, and reference electrodes, respectively. To define the nanorods structure polycarbonate membranes $\left(20-\mu \mathrm{m}\right.$ thick, $100 \mathrm{~nm}$ nominal pore diameter and $10^{8}$ to $2.510^{9}$ pores $\mathrm{cm}^{-2}$ pore density with $100 \mathrm{~nm}$-thick gold layer in one side, which enabled conductivity) were used as working electrodes. After nanorod synthesis, the Au layer was removed by etching the $\mathrm{Au}$ using a saturated solution of $\mathrm{I}_{2} / \mathrm{I}^{-}$, and under ultrasonic stirring, the PC membranes were dissolved with chloroform (x5), and washed with chloroform (x10), ethanol (x5), and Millipore water (x5). Nanorods were also immersed in $0.1 \mathrm{M} \mathrm{NaOH}$ (x3) prior to being washed in Millipore water when microemulsions were employed. Lastly, after the cleaning procedure, a thin, nanometric shell of gold formed via galvanic displacement, which consisted of immersing in $2.9 \mathrm{mM}$ of $\mathrm{HAuCl}_{4}$ solution.

The morphology and structure of the CoNi@ Au nanorods were examined by using transmission electron microscopy (Jeol 2100). Elemental composition was measured using electron probe microanalysis by energy-dispersive X-ray analysis (Cameca SX-50 equipment) or an X-ray analyzer incorporated in Leica Stereoscan $^{\mathrm{TM}}$ S-360 equipment. XRD patterns were registered by means of a Philips MRD diffractometer with parallel optical geometry using a $\mathrm{Cu} \mathrm{K}_{\alpha}$ radiation $(\lambda=1.5418 \AA)$. The electrochemical surface area of the different prepared nanorods was obtained by integrating the charge associated with the reduction of gold oxide, which was proportional to the real active surface area of the gold surface, in cyclic voltammograms recorded in $\mathrm{H}_{2} \mathrm{SO}_{4}$. Electrochemical surface area were estimated assuming that the charge required to reduce gold oxide was $390 \mu \mathrm{C} \mathrm{cm}^{-2}{ }^{[22]}$

Nanorod functionalization and drug loading: Nanorods $(900 \mu \mathrm{g})$ were functionalized by immersion in $2 \mathrm{~mL}$ of nonpolar organic thiol (1.7 mM HS-PEG) with or without the selected drug $(1.6 \mathrm{mM}$ irinotecan hydrochloride - Afine Chemicals ,Hangzhou, China - which was pure, with a minimal grade of 99\%.). Nanorod functionalization was corroborated by means of electrochemical probe experiments, namely by recording cyclic voltammetries of the $\mathrm{Fe}(\mathrm{II}) / \mathrm{Fe}(\mathrm{III})$ system in a $\mathrm{KNO}_{3} 0.2 \mathrm{M}+2 \mathrm{mM}$ $\mathrm{K}_{4}\left[\mathrm{Fe}(\mathrm{CN})_{6}\right]+2 \mathrm{mM} \mathrm{K} \mathrm{K}_{3}\left[\mathrm{Fe}(\mathrm{CN})_{6}\right]$ solution. For each experiment, suspensions of functionalized and nonfunctionalized nanorods were dropped onto the surface of a GC electrode (Metrohm) rod of 0.0314 $\mathrm{cm}^{2}$ and dried under nitrogen flow. Drug retention analysis was performed by fluorescence emission and excitation spectra $\left(\lambda_{\mathrm{ex}}=278 \mathrm{~nm}\right)$ using an AMINCO-Bowman Series 2 spectrofluorometer with a 
micro-cell $(1 \mathrm{~mL})$ at $25^{\circ} \mathrm{C}$. To determine the concentration of drug released, a calibration curve was necessary, which involved comparing the unknown concentration to a set of standard samples of known concentrations.

Cell culture: Experiments were performed on the tumoral epithelial cell line HeLa originated from a cervix adenocarcinoma. HeLa cells were grown as monolayers in Dulbecco's modified Eagle's medium (DMEM) supplemented with $50 \mathrm{U} \mathrm{mL}^{-1}$ penicillin, $50 \mu \mathrm{g} \mathrm{mL}^{-1}$ streptomycin, $292 \mathrm{mg} \mathrm{mL}^{-1} \mathrm{~L}$-glutamine, $1 \%$ nonessential amino acids, and fetal bovine serum (FBS) at a final concentration of $10 \% ; 4.5 \mathrm{~g}$ glucose $\mathrm{L}^{-1}$ (DMEM), fetal calf serum, penicillin-streptomycin, nonessential amino acids and Lglutamine solutions were provided by from Biological Industries (Beit HaEmek, Israel). Cell cultures were performed in a humidified sterile atmosphere of $95 \%$ air and $5 \% \mathrm{CO}_{2}$ at $37{ }^{\circ} \mathrm{C}$ in a SteriCult 200 incubator (Hucoa-Erloss). HeLa cells were seeded in $25 \mathrm{~cm}^{2}$ flasks (90,000 cells), in $35 \mathrm{~mm}$ Petri dishes (25,000 cells) or in an 8 well Nunc ${ }^{\mathrm{TM}}$ Lab-Tek $^{\mathrm{TM}}$ II Chambered Coverglass (Thermo Scientific, USA) for confocal microscope studies. Cells were grown for $72 \mathrm{~h}$ and treated when cultures achieved exponential growth. All sterile plastics were from Corning (Corning, NY, USA).

Cells treatment: The effect of nanorods with and without CPT-11 upon cell survival in silent conditions $(0 \mathrm{~Hz})$ and in the external rotatory magnetic field $(20 \mathrm{~Hz})$ was determined. HeLa cells seeded in $35 \mathrm{~mm}$ Petri dishes were cultured until reaching $70-75 \%$ confluence and incubated for $24 \mathrm{~h}$ with functionalized nanorods (20 $\mu \mathrm{g}$ nanorods $\left.\mathrm{mL}^{-1} \mathrm{DMEM}\right)$, with and without CPT-11, in lactate buffer (10 mM pH 4.4). The cells were next washed 3 times with sterile Dulbecco's phosphate buffered saline (PBS), supplemented with fresh medium and incubated for another $24 \mathrm{~h}$ in silent conditions. To test the influence of an external rotatory magnetic field, the magnetic field $(20 \mathrm{~Hz})$ was applied for $30 \mathrm{~min}$ after washing with PBS. Cell survival was evaluated after $24 \mathrm{~h}$ of postincubation in a fresh medium by MTT (3-[4,5-dimethylthiazol-2-yl]-2,5-diphenyltetrazolium bromide) assay, which detected only living cells. ${ }^{[23]}$ That assay was based on the reduction of tetrazolium salt to form a formazan dye using the electrons from the mitochondria of viable cells. The appropriate amount of a MTT stock solution $\left(1 \mathrm{mg} \mathrm{mL} \mathrm{mL}^{-1}\right.$ PBS) was added to DMEM for a final concentration of $47,6 \mu \mathrm{g} \mathrm{mL}^{-1}$. The medium without MTT was withdrawn and replaced by the medium supplemented with the dye. Cells were incubated for $3 \mathrm{~h}$ at $37^{\circ} \mathrm{C}$, 
and to dissolve formazan precipitates, the medium was replaced by DMSO. Absorbance was measured at $526 \mathrm{~nm}$ on a Synergy H1 microplate spectrofluorimeter $\left(\right.$ SynergyMX ${ }^{\mathrm{TM}}$, BioTek Instruments, Winooski, VT, USA). Cell survival was expressed as the percentage of absorption of treated cells in relation to that of control cells (100\% survival).

Confocal microscopy: Confocal microscopy was used to verify nanorods internalization. Cells were grown in an 8 well Nunc ${ }^{\mathrm{TM}}$ Lab-Tek $^{\mathrm{TM}}$ II Chambered Coverglass. First, cells were incubated at $37^{\circ} \mathrm{C}$ for $18 \mathrm{~h}$ with a suspension of the corresponding CoNi@Au-HS-PEG nanorods in DMEM (20 $\mu \mathrm{g}$ nanorods $\mathrm{mL}^{-1}$ ) to allow their internalization. To confirm the intracellular localization of the nanorods, the cytoplasm of the cells was labeled with green CellTracker ${ }^{\mathrm{TM}}$ fluorescent probe CMFDA in serum-free culture medium, which acted as a cell tracker (C7025 Thermo Fisher, Life Technologies). The method of labeling consisted of five steps: (1) washing cells twice for 5 min with PBS, (2) incubating them for $30 \mathrm{~min}$ at $37^{\circ} \mathrm{C}$ with the binding solution ( $5 \mu \mathrm{M}$ CMFDA in serum-free culture medium), (3) washing them twice for 5 min with PBS, (4) incubating them for 30 additional min at $37^{\circ} \mathrm{C}$ with supplemented cell culture medium, and (5) ultimately washing them twice for $5 \mathrm{~min}$ with PBS. After labeling, the cells were maintained in complete culture medium containing $10 \mathrm{mM}$ HEPES to keep them alive during their observation with the microscope. HeLa cells were imaged using a Leica TCS SP2 confocal laser fluorescence microscope (Heidelberg, Germany) with simultaneous fluorescence and reflection acquisition, by using an argon laser of $488 \mathrm{~nm}$. Different sections were initially scanned, and a data set of z-series images were collected from the bottom to top of the wells in the direction of the z-axis. Threedimensional reconstructions were made with Imaris 7.2.3 (Bitplane AG, Zurich, Switzerland).

\section{Supporting Information}

Supporting Information is available from the Wiley Online Library or from the author.

\section{Acknowledgements}

This work was supported by the EU ERDF (FEDER) funds and the Spanish Government grant TEC2014-51940-C2-2-R from Ministerio de Economía y Competitividad (MINECO). Albert Serrà thanks the Ministerio de Educación, Cultura y Deporte for a predoctoral grant (FPU). Authors thank the CCiT-UB for the use of their equipment. Authors are also grateful to Dr. Raimundo Gargallo (Department of Analytical Chemistry, University of Barcelona) for his 
support in the fluorimetry experiments and to Dr. Manel Bosch (Advanced Optical Microscopy Unit of the CCiT-UB) for his helpful technical support in the confocal experiments.

Received: ((will be filled in by the editorial staff))

Revised: ((will be filled in by the editorial staff)) Published online: ((will be filled in by the editorial staff))

[1] a) N. Nasongkla, E. Bey, J. Ren, A. Hua, C. Khemtong, J.S. Guthi, S.-F. Chin, A.D. Sherry, D.A. Boothman, J. Gao, Nano Lett. 2006, 6, 2427; b) P. Kesharwani, K. Jain, N.K. Jain, Prog. Polym. Sci. 2014, 39, 268; c) J.C. Kraft, J.P. Freeling, Z. Wang, R.J.Y. Ho, J. Pharm. Sci. 2014, 103, 29; d) D.M. Copolovic, K. Langel, E. Eriste, U. Langel, ACS Nano, 2014, 8, 1972; e) J. Kreuter, Adv. Drug. Deliv. Rev., 2014, 71, 2; f) A. Wicki, D. Witzigmann, V. Balasubramanian, J. Huwyler, J. Control. Rel. 2015, 200, 138.

[2] a) A.V. Kabanov, E.V. Batrakova, V.Y. Alakhov, J. Control. Rel. 2002, 82, 189; b) L.C. Glangchai, M. Caldorera-Moore, L. Shi, K. Roy, J. Control. Rel. 2008, 125, 263; c) S. Panja, S. Maji, T.K. Maiti, S.A. Chattopadhyay, ACS Appl. Mater. Interfaces. 2015, 7, 24229.

[3] a) M. García-Díaz, M. Kawakubo, P. Mroz, M.L. Sagristá. M. Mora, S. Nonell, M.R. Hamblin, J. Control. Rel. 2012, 162, 355; b) A. Casadó, M.L. Sagristà, M. Mora, J. Pharm. Sci., 2014, $103,3127$.

[4] a) W. Park, B.-C. Bae, K. Na, Biomaterials, 2016, 77, 227; b) Y. Shamay, L. Adar, G. Ashkenasy, A. David, Biomaterials, 2011, 32, 1377; c) L. Momtazi, S. Bagherifam, G. Singh, A. Hofgaard, M. Hakkarainen, W.R. Glomm, N. Roos, G.M. Maelandsmo, G. Griffiths, B. Nyström. Langmuir, 2014, 433, 76; d) F. Liu, V. Kozlovskaya, S. Medipelli, B. Xue, F. Ahmad, M. Saeed, D. Cropek, E. Kharlampieva, Chem. Mater., 2015, 27, 7945; e) Y. Wen, J.K. Oh, Colloid Surface. B, 2015, 133, 246.

[5] a) L.A. Torre, F. Bray, R.L. Siegel, J. Ferlay, J. Lortet-Tieulent, A. Jernal, CA-Cancer J. Clin. 2015, 65, 87; b) J. Ferlay, I. Soerjomatarm, R. Dikshit, S. Eser, C. Mathers, M. Rebelo, D.M. Parkin, D. Forman, F. Bray, Int. J. Cancer., 2015, 136, 359; c) J. Ferlay, E. Steliarova-Foucher, J. Lortet-Tieulent, S. Rosso, J.W.W. Coebergh, H. Comber, D. Forman, F. Bray, Eur. J. Cancer., 


\section{WILEY-VCH}

2013, 49, 1374; d) M. Arnold, H.E. Karim-Kos, J.W. Coebergh, G. Byrnes, A. Antilla, J. Ferlay, A.G. Renehan, D. Forman, I. Soerjomatarm, Eur. J. Cancer., 2015, 51, 1164.

[6] a) K. Suda, K. Sato, H. Mizuuchi, Y. Kobayashi, M. Shimoji, K. Tomizawa, T. Takemoto, T. Iwasaki, M. Sakaguchi, T. Mitsudomi, Resp. Investigation, 2014, 52, 322; b) S. Singhal, L.R. Kaiser, Surg. Oncol. N. Am., 1998, 7, 505; c) G.N. Marta, F.Y. De Moraes, Exp. Rev. Anticancer Ther. 2015, 15, 1257.

[7] a) J. Tabernero, E.V. Cutsem, R. Lakomy, J. Parausová, P. Ruff, G.A. Van Hazel, V.M. Moiseyenko, D.R. Ferry, J.J McKendrick, K. Soussan-Lazardi, S. Chevalier, C.J. Allerga, Eur. J. Cancer., 2014, 50, 320; b) C. Fuchs, E.P. Mitchell, P.M. Hoff, Cancer Treat. Rev., 2006, 32, 491; c) M.Z. Ahmad, S. Akhter, M. Anwar, A. Kumar, M. Rahman, A.H. Talasaz, F.J. Ahmad, Drug. Dev. Inv. Pharm., 2013, 39, 1936.

[8] a) M.J. O'Connell, J. Clin. Oncol. 2009, 27, 3082; b) V.P. Torchilin, Nat. Rev. Drug. Discov., 2014, 13, 813; c) S. Mura, J. Nicolas, P. Couvreur, Nat. Mat., 2013, 991; d) C.L. Weaver, J.M. LaRosa, X. Luo, X.T. Cui, ACS Nano, 2014, 8, 1834; e) J. Di, S. Yao, Y. Ye, Z. Cui, J. Yu, T.K. Ghosh, Y. Zhu, Z. Gu, ACS Nano, 2015, 9, 9407-9415.

[9] M. García-Díaz, S. Nonell, A. Villanueva, J.C. Stockert, M. Cañete, A. Casadó, M. Mora, M.L. Sagristá, Biochim. Biophys. Acta, 2011, 1808, 1063.

[10] a) K.M. Pondman, N.D. Bunt, A.W. Maijenburg, R.J.A. Van Wezel, U. Kishore, L. Abelman, J.E. Ten Elshof, B. Ten Haken, J. Mag. Mag. Mater., 2015, 380, 299; b) K.M. Pondman, A.W. Maijenburg, F.B. Celikkol, A.A. Pathan, U. Kishore, B. Ten Haken, J.E.Ten Elshof, J. Mater. Chem., 2013, 1, 6129; c) S.N. Tabatabaei, H. Girouard, A.-S. Carret, S. Martel, J. Control Rel., 2015, 206, 49; d) J. Wang, C. Gong, Y. Wang, G. Wu, Colloid Surface. B, 2014, 118, 218.

[11] a) K. Tschulik, K. Ngamchuea, C. Ziegler, M.G. Beier, C. Damm, A. Eychmueller, R.C. Compton, Adv. Funct. Mater., 2015, 25, 5149; b) M.F. Contreras, R. Sougrat, A. Zaher, T. Ravasi, J. Kosel, J. Nanomedicine, 2015, 10, 2141; c) K. Giannousi, M. Menelaou, J. Arvanitidis, M. Angelakeris, A. Pantazaki, C. Dendrinou-Samara, J. Mater. Chem. B, 2015, 5341. 


\section{WILEY-VCH}

[12] a) D.-H. Kim, E.A. Rozhkova, I.V. Ulasov, S.D. Bader, T. Rajh, M.S. Lesniak, V. Novosad, Nat. Mat., 2010, 9, 165; b) T. Vemulkar, R. Mansell, D.C.M.C. Petit, R.P. Cowburn, M.S. Lesniak, Appl. Phys. Lett. 2015, 107, 012403; c) P. Tiberto, G. Barrera, F. Celegato, G. Conta, M. Coïsson, F. Vinai, F. Albertini, J. Appl. Phys. 2015, 117, 17 B304.

[13] a) C. Gispert, A. Serrà, M.A. Alea, M. Rodrigues, E. Gómez, M. Mora, M.L. Sagristà, L. PérezGarcia, E. Vallés, Electrochem. Comm. 2016, 63, 18; b) N. Choi, Y. Guan, L. Yang, L. Jia, X. Wei, H. Liu, C. Guo, C, J. Colloid Interface Sci. 2013, 395, 50.

[14] a) K. Keshoju, H. Xing, L. Sun, Appl. Phys. Lett. 2007, 91, 123114; b) A. Güntherm, P. Bender, A. Tschöpe, R. Birringer, J. Phys. Conden. Matter. 2011, 23, 325103.

[15] a) R. Ferré, K. Ounadjela, J.M. George, L. Piraux, S. Dubois, Physical Review. B. 1997, 56, 66; b) Y. Zhao, H. Zeng, IEEE Trans Nanobioscience. 2009, 8, 226; c) N. Gao, H. Wang, E. H. Yang, Nanotechnology, 2010, 21, 105107; d) D. Choi, A . Fung, H. Moon, D. Ho, Y. Chen, E. Kan, Y. Rheem, B. Yoo, N. Myung, Biomed. Microdevices., 2007, 9, 143; e) A. Hultgren, M. Tanase, C. S. Chen, G. J. Meyer, D. H. Reich, J. Appl. Phys. 2003, 93, 7554; f) A. Hultgren, M. Tanase, E. J. Felton, K. Bhadriraju, A. K. Salem, C. S. Chen, D. H. Reich, Biotechnol. Prog. $\mathbf{2 0 0 5}, 21,509$.

[16] a) Y. Rheem, B.-Y. Yoo, W.P. Beyermann, N.V. Myung, Nanotech. 2007, 18, 125204; b) J. Vilana, E. Gómez, E. Vallés, J. Electroanal. Chem. 2013, 703, 88.

[17] a) A. Serrà, E. Gómez, E. Vallés, Electrochim. Acta. 2015, 174, 630; b) Int. J. Hydrog. Energy, 2015, 40, 8062; c) A. Serrà, E. Gómez, I. V. Golosovsky, J. Nogués, E. Vallés, J. Mater. Chem. $A, \mathbf{2 0 1 6}, 4,7805$.

[18] a) J. Vilana, R. Amade, S. Hussain, E. Bertran, E. Gómez, E. Vallés, Mat. Lett. 2014, 124, 8; b) G. Ali, M. Maqbool, Nano. Res. Lett. 2013, 8, 352.

[19] a) A. Serrà, E. Gómez, J.F. López-Barbera, J. Nogués, E. Vallés, ACS Nano, 2014, 8, 4630; b) Y. Gao, S. Han, B. Han, G. Li, D. Shen, Z. Li, J. Du, W. Hou, G. Zhang, Langmuir, 20005, 21, 568. 


\section{WILEY-VCH}

[20] a) X. Liu, A. Situ, Y. Kang, K. R. Villabroza, Y. Liao, C. H. Chang, T. Donahue, A. E. Nel, H. Meng, ACS Nano, 2016, 10, 2702; b) S. Nastase, L. Bajenaru, D. Berger, C. Matei, M. G. Moisescu, D. Constantin, T. Savopol, Cen. Eur. J. Chem. 2014, 12, 813.

[21] a) R.P. Haugland, Handbook of Fluorescent Probes and Research Chemicals. Seventh edition. Eugene, Oregon (available on CDROM), 1999; b) G. Packroff, J.R. Lawrence, T.R. Neu, Acta Protozoool. 2002, 41, 245; c) K.S. Ralston, M.D. Solga, N.M. Mackey-Lawrence, A. Somlata, A. Bhattacharya, W.A. Petri Jr, W.A. Nature 2014, 508, 526.

[22] a) S. Trasatti, O.A. Petrii, Pure \& Appl. Chem., 1991, 63, 711; b) F. Jia, C. Yu, Z. Ai, L. Zhang, Chem. Mater. 2007, 19, 3648.

[23] a) T. Mosmann J. Immunol. Methods 1983, 65, 55; b) 


\section{WILEY-VCH}
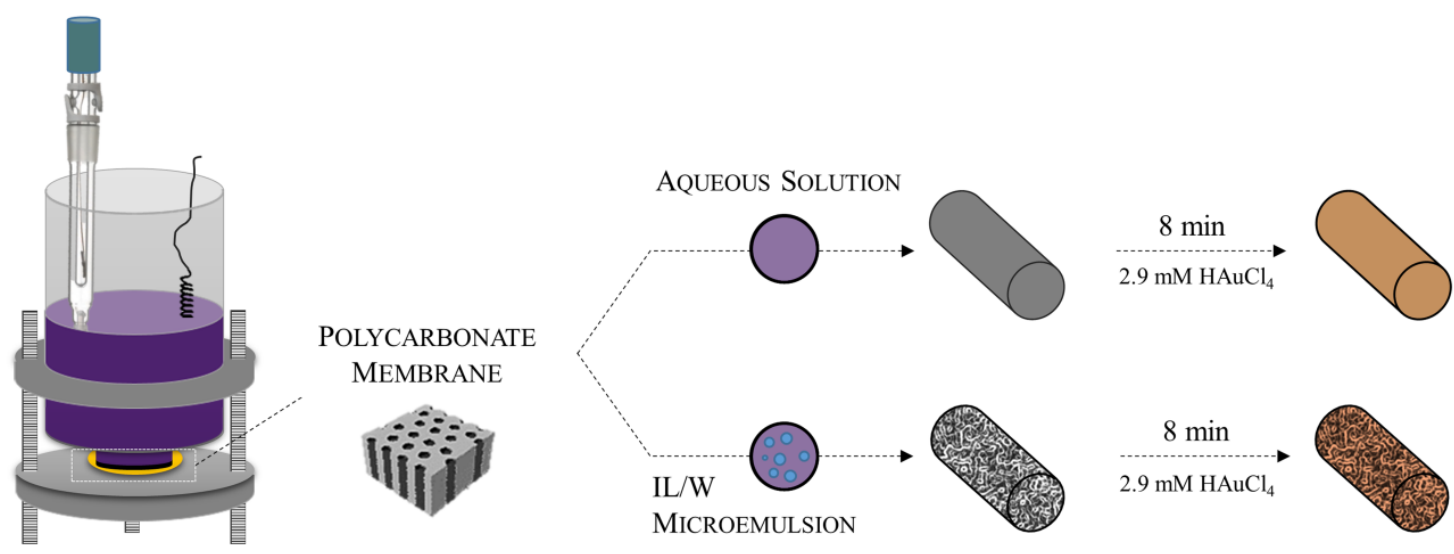

Figure 1: Schematic representation of electrochemical synthesis of magnetic CoNi@ Au NRs in aqueous solution and IL/W microemulsions. 


\section{WILEY-VCH}
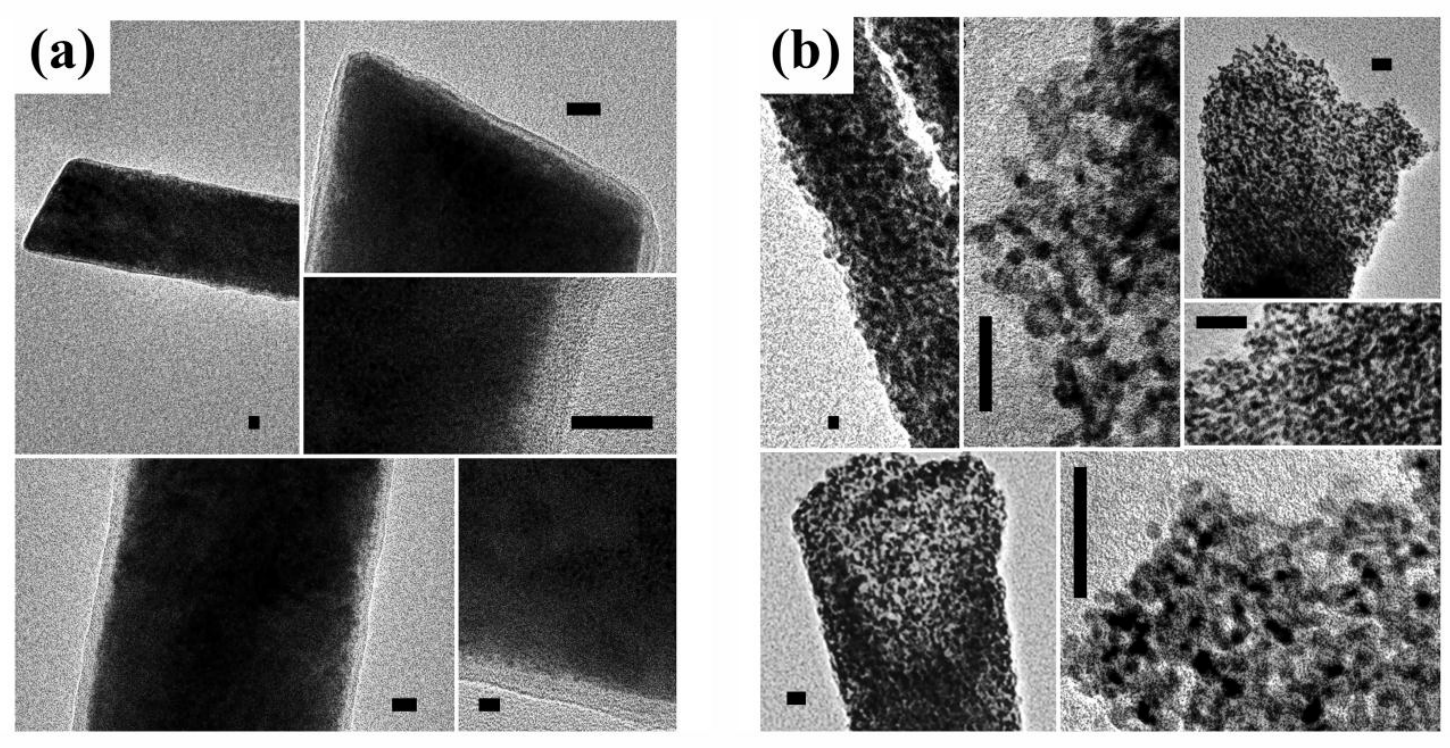

(c)

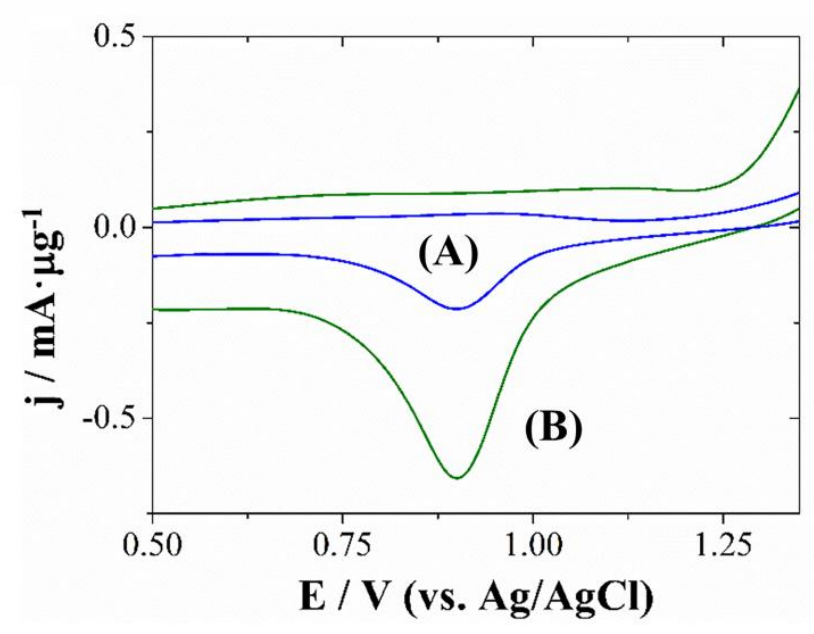

Figure 2: Transmission electron micrographs of the magnetic compact (a) and mesoporous (b) CoNi@Au NRs. (c) Cyclic voltammetry (first cycle) of compact (A) and mesoporous (B) CoNi@Au NRs in $\mathrm{H}_{2} \mathrm{SO}_{4} 0.5 \mathrm{M}$ solutions at room temperature at the scan rate of $100 \mathrm{mV} \mathrm{s}^{-1}$. Scale bar: $10 \mathrm{~nm}$. 
(a)
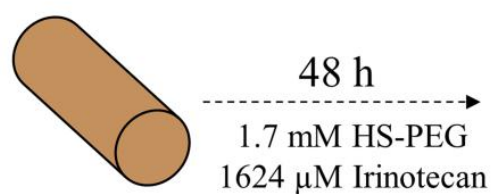

$1624 \mu \mathrm{M}$ Irinotecan $800 \mathrm{rpm}$

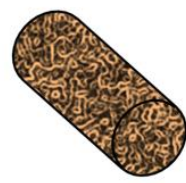

$$
\begin{gathered}
48 \mathrm{~h} \\
1.7 \mathrm{mM} \text { HS-PEG } \\
1624 \mu \mathrm{M} \text { Irinotecan } \\
800 \mathrm{rpm}
\end{gathered}
$$

- Irinotecan Hydrochloride HS-PEG (b)
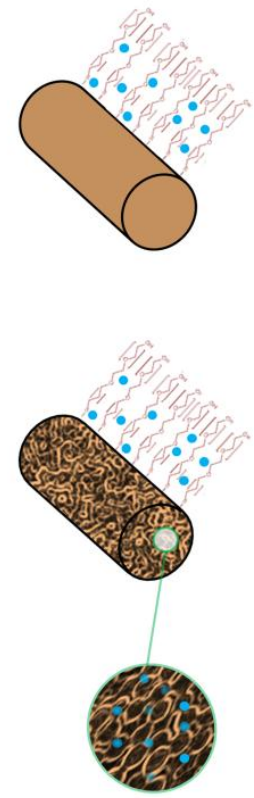

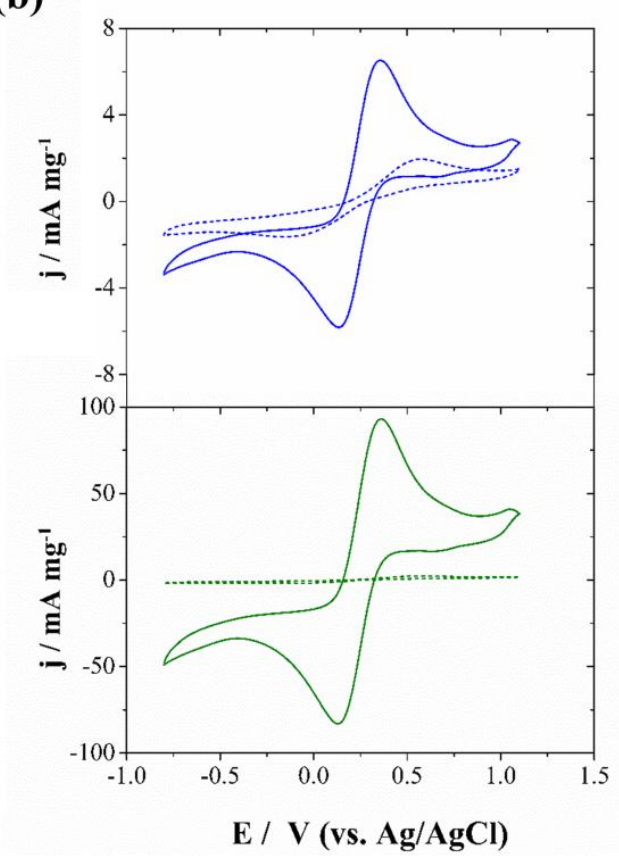

Figure 3: (a) Schematic representation of nanorod functionalization with HS-PEG and drug loading. (b) Cyclic voltammetries of the $\mathrm{Fe}(\mathrm{II}) / \mathrm{Fe}$ (III) system in a $\mathrm{KNO}_{3} 0.2 \mathrm{M}+\mathrm{K}_{4}\left[\mathrm{Fe}(\mathrm{CN})_{6}\right]$ $2 \mathrm{mM}+\mathrm{K}_{3}\left[\mathrm{Fe}(\mathrm{CN})_{6}\right] 2 \mathrm{mM}$ solution on compact (blue lines) and mesoporous (green lines) CoNi@Au (continuous lines) and in CoNi@Au-SH-PEG nanorods (dashed lines) placed on glassy carbon electrodes, at room temperature and at scan rate of $100 \mathrm{mV} \mathrm{s}^{-1}$. 


\section{WILEY-VCH}

(a)
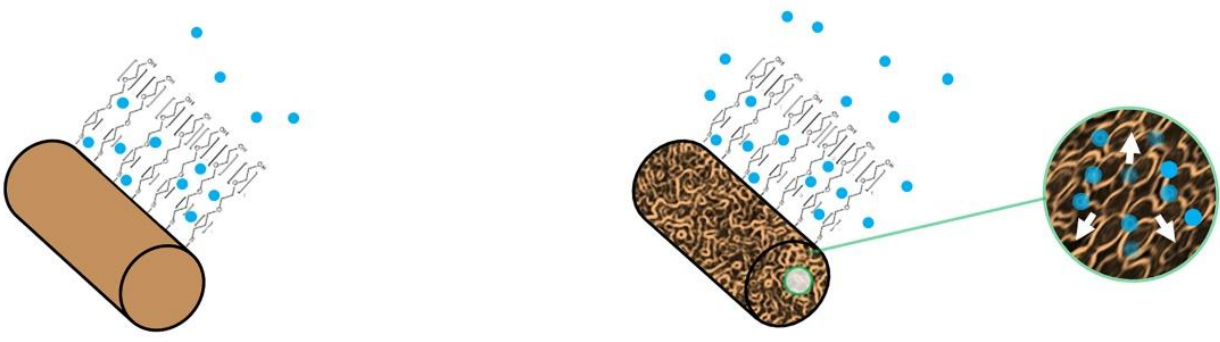

$\mathbf{0 ~ H z}$

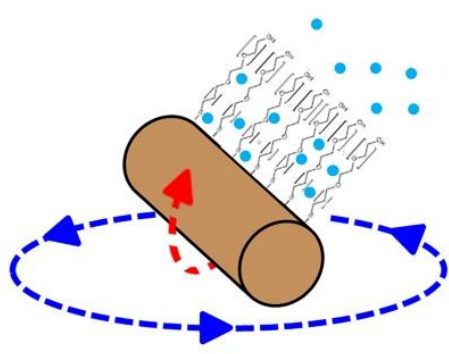

$20 \mathrm{~Hz}$

(b)

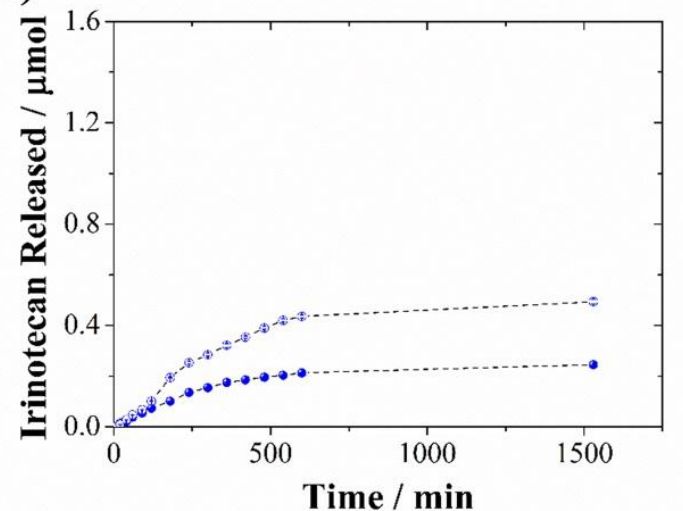

(d)

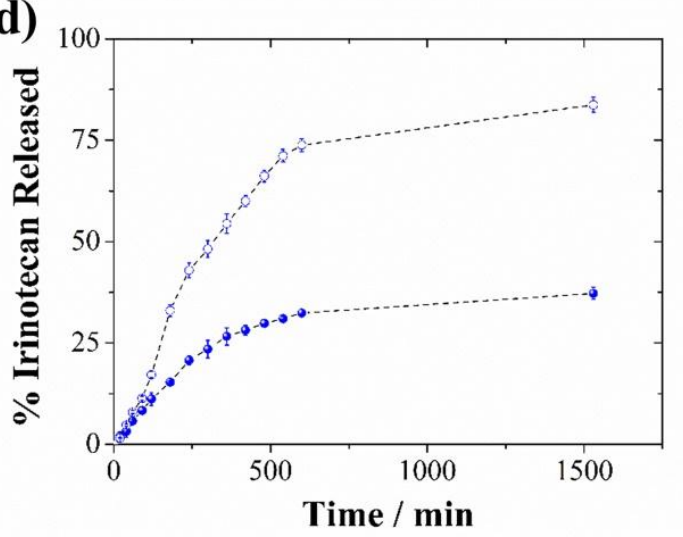

(c)

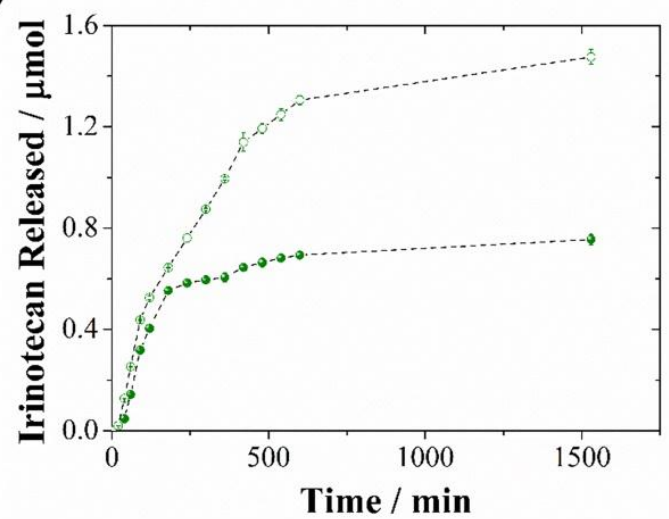

(e)

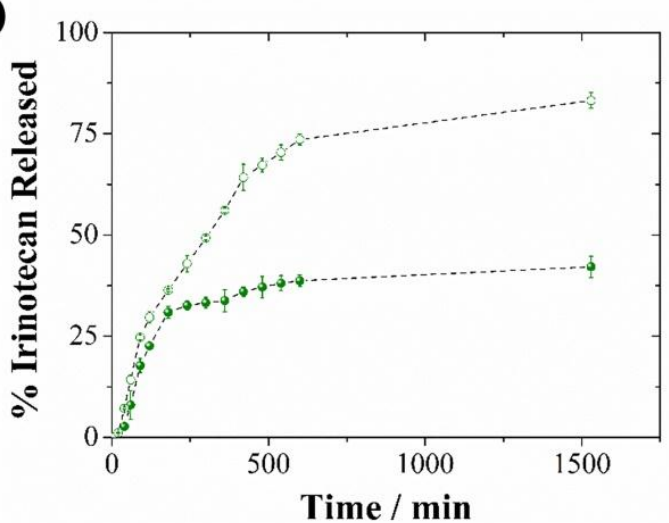

Figure 4: (a) Schematic representation of CPT-11 release from magnetic compact (left) and mesoporous (right) CoNi@Au nanorods loaded with the drug in static conditions (upper) and 
under the influence of an external rotatory magnetic field of $20 \mathrm{~Hz}$ (bottom). (b - e) Influence of the application of the external rotatory magnetic field on CPT-11 release from compact (b, d) and mesoporous (c, e) CoNi@Au nanorods (450 $\mu \mathrm{g})$ expressed as the $\mu$ mol of CPT-11 released $(b, c)$ or as the percentage of the drug released $(d, e)$ in static conditions (closed symbols) and under the influence of a magnetic external rotatory field (open symbols).

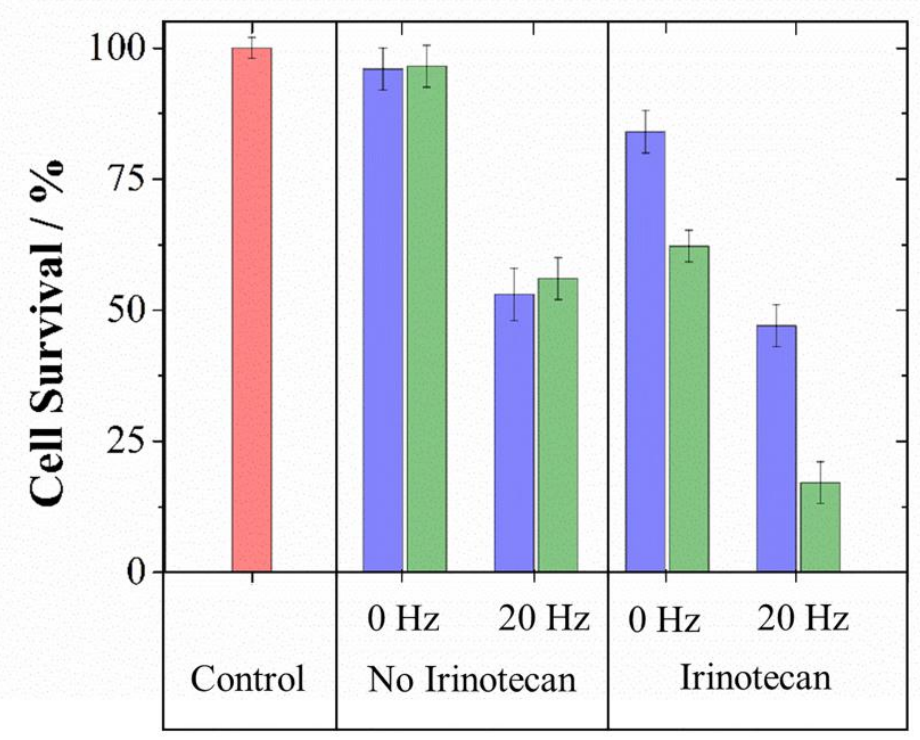

Figure 5: Surviving fraction of HeLa cells incubated with CPT-11 (left) for $48 \mathrm{~h}$ with cell culture medium, to which a $100 \%$ survival control was assigned; (middle) with $20 \mu \mathrm{g}$ of empty compact (blue) or mesoporous (green) CoNi@Au-SH-PEG nanorods $\mathrm{mL}^{-1}$ in silent $(0 \mathrm{~Hz})$ and under a rotatory external magnetic field $(20 \mathrm{~Hz})$; and (right) incubated with $20 \mu \mathrm{g}$ of drugloaded compact (blue) or mesoporous (green) CoNi@ Au-SH-PEG nanorods $\mathrm{mL}^{-1}$ in silent (0 $\mathrm{Hz})$ and under a rotatory external magnetic field $(20 \mathrm{~Hz})$. CPT-11 content in incubates was 0.0013 or $0.0040 \mu \mathrm{mol} \mu \mathrm{g}^{-1}$, respectively, with compact and mesoporous nanorods. 


\section{WILEY-VCH}

(a)

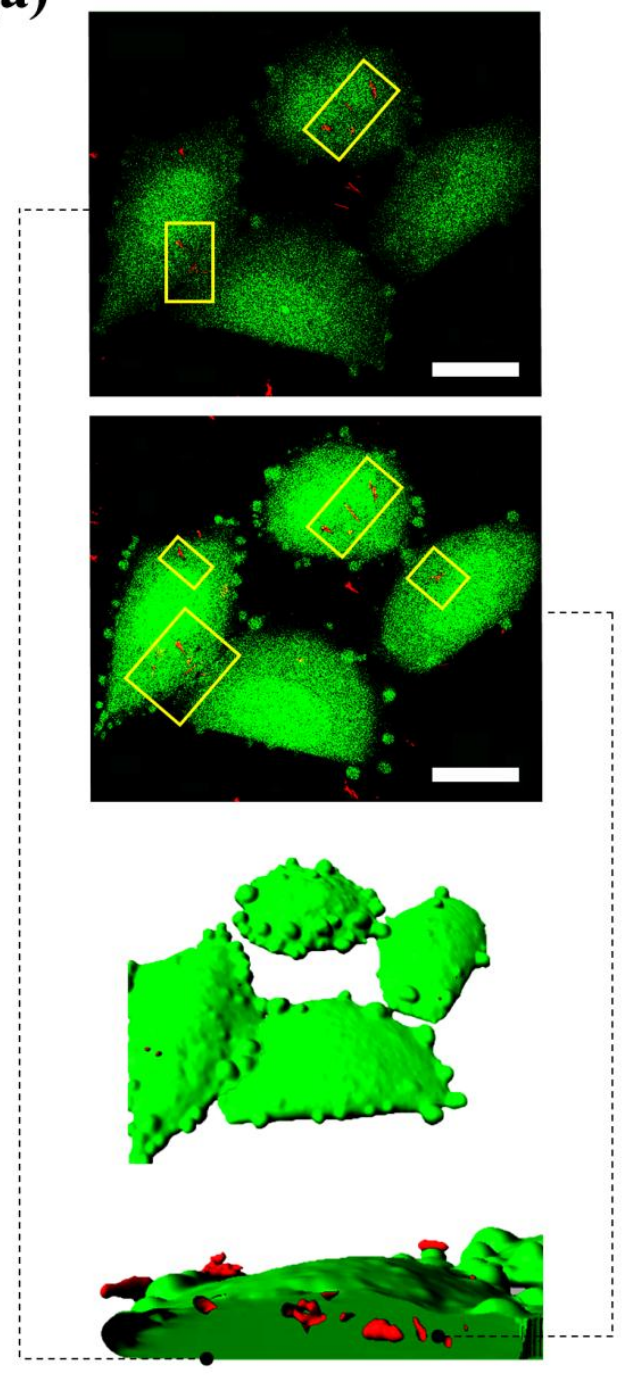

(b)
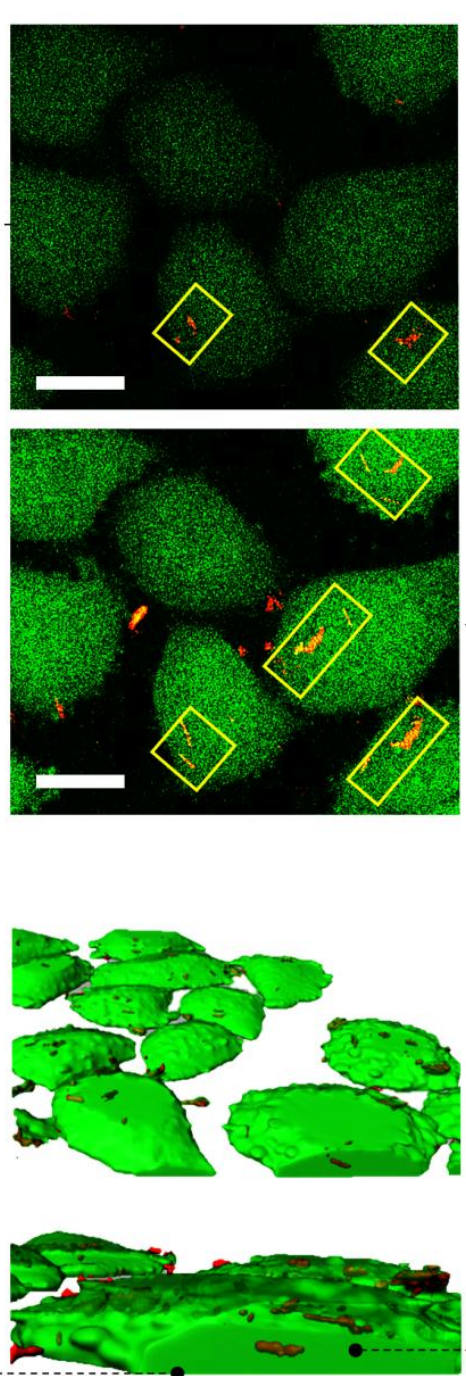

Figure 6: Internalization of compact (left) and mesoporous (right) CoNi@Au-SH-PEG nanorods by HeLa cells; HeLa cells cytoplasm stained with 5-chloromethylfluorescein diacetate is shown in green, and nanorods visualized by reflection are marked in red. Images are representative of two independent experiments: a 3-dimensional reconstruction of HeLa cells (bottom) and sections of HeLa cells acquired during scanning (top). Scale bar: $20 \mu \mathrm{m}$. 
Table 1: Working Potential, Deposition Charge, Length, Diameter, Elemental Composition, and Shell Thickness of Nanorods.

\begin{tabular}{|c|c|c|c|c|c|c|c|c|}
\hline & $\begin{array}{c}\text { Potential / } \\
\text { mV }\end{array}$ & $\begin{array}{l}\text { Deposition } \\
\text { charge / C }\end{array}$ & $\begin{array}{l}\text { Length } \\
/ \mu \mathrm{m}\end{array}$ & $\begin{array}{c}\text { Diameter / } \\
\mathbf{n m}\end{array}$ & com & $\begin{array}{l}\text { mer } \\
\text { sitic } \\
\%\end{array}$ & wt. & $\begin{array}{c}\text { Shell } \\
\text { Thickness / } \\
\text { nm }\end{array}$ \\
\hline & & & & & Co & $\mathbf{N i}$ & $\mathrm{Au}$ & \\
\hline $\begin{array}{l}\text { Compact } \\
\text { CoNi@Au }\end{array}$ & -1000 & -2.5 & $1.8 \pm 0.4$ & $104 \pm 9$ & 34 & 39 & 27 & 0.7 \\
\hline $\begin{array}{c}\text { Mesoporous } \\
\text { CoNi@Au }\end{array}$ & -1000 & -2.5 & $1.7 \pm 0.4$ & $107 \pm 12$ & 29 & 31 & 40 & 0.1 \\
\hline
\end{tabular}




\section{WILEY-VCH}

A new versatile and simple procedure to grow magnetic mesoporous nanorods is proposed, by a first time, as magnetic drug nanocarriers with excellent drug-loading and improved therapeutic efficacy. The nanostructures present low toxicity but when are loaded with a carcinogenic drug, induced cell death as a combination of both mechanical and drug death, making them excellent candidates for drug delivery.

Keyword: drug delivery, mesoporous magnetic carriers, nanorods, microemulsions, irinotecan (CPT-11).

Albert Serrà, Núria Gimeno, Elvira Gómez, Margarita Mora, Maria Lluïsa Sagristà, and Elisa Vallés*

Magnetic mesoporous nanocarriers for drug delivery with improved therapeutic efficacy

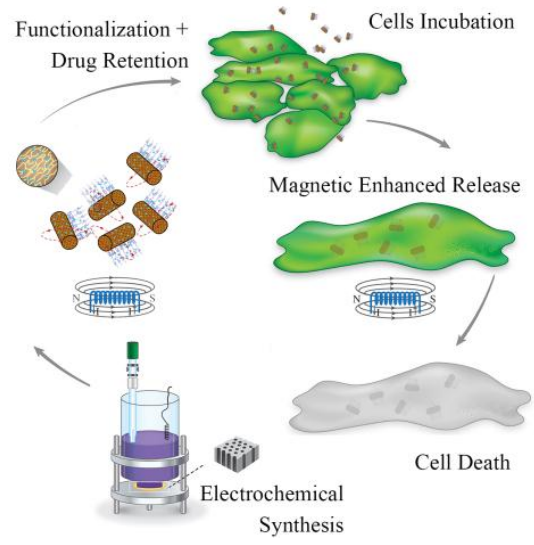




\section{WILEY-VCH}

Copyright WILEY-VCH Verlag GmbH \& Co. KGaA, 69469 Weinheim, Germany, 2013.

Supporting Information

Magnetic mesoporous nanocarriers for drug delivery with improved therapeutic efficacy

Albert Serrà, Núria Gimeno, Elvira Gómez, Margarita Mora, Maria Lluïsa Sagristà, and Elisa Vallés* 


\section{WILEY-VCH}

\section{Cyclic voltammetries}

Voltammetric curves were recorded on $\mathrm{Si} / \mathrm{Ti}(15 \mathrm{~nm}) / \mathrm{Au}(100 \mathrm{~nm})$ substrates (Figure 1S) in order to interpret the CoNi electrodeposition process in the microemulsion and to select the potentials able to form the CoNi mesostructures over gold surfaces. The blue curve (Figure 1Sa) corresponds to the typical profile of a CoNi deposition process in an aqueous solution: with the nucleation and the growth loop in the cathodic scan, and the oxidation peak corresponding to the alloy oxidation. When both surfactant and ionic liquid are added to the aqueous solution to form the microemulsion, the voltammetric profile changes. To justify this change, cyclic voltammetries of aqueous solution containing surfactant (Figure 1Sb) and of the microemulsion at different cathodic limits (Figure 1Sc) were recorded. The presence of the surfactant in the CoNi aqueous solution leads to a small reduction peak prior to the main alloy deposition current (Figure 1Sb, cathodic limit $-0.8 \mathrm{~V}$ ). We can assign this first reduction peak to the initial deposition of nickel or nickel-rich deposit, over which the anomalous codeposition of CoNi takes place. The presence of the surfactant hinders the adsorption of the Co (II) species proposed in the mechanism of the anomalous CoNi electrodeposition, ${ }^{[1]}$ as the manner that the initial step of normal electrodeposition is detected.

The voltammetries in the ionic liquid-in-CoNi aqueous solution microemulsion also shows a first reduction peak at around $-0.6 \mathrm{~V}$, assigned to the initial nickel deposition, followed by a main reduction peak assigned to the CoNi deposition. In the first reduction peak, the accumulation of deposit by means of a hold allows detecting the oxidation peak corresponding to the first nickel-rich deposit formed at potentials prior to the oxidation of the CoNi alloy.

When deposits were prepared from the three electrodeposition media (CoNi aqueous solution W-, solution containing surfactant $-\mathrm{W}+\mathrm{S}-$, and IL/W microemulsion) the previous proposal is corroborated. In both $\mathrm{W}+\mathrm{S}$ and IL/W systems, the obtained deposits at low deposition potentials $(-650 \mathrm{mV})$ are nickel-rich, which is justified by the nobler character of this metal respect to the cobalt (Table 1S). At more negative potentials, the CoNi alloy is already formed, and 


\section{WILEY-VCH}

anomalous codeposition takes place, because the composition of the deposits are cobalt richer than that of the obtained in CoNi solution. In the case of the $\mathrm{W}$ system, the initial nickel deposition is not observed, as has been found previously.

From the performed voltammetric study, we can select potentials equal or more negative than $-900 \mathrm{mV}$ to assure the formation of the CoNi alloy from the IL/W microemulsion. In order to obtain the same composition of the CoNi structures from aqueous solution $\mathrm{W}$ (compact structures) or IL/W microemulsion (mesoporous structures) over gold substrate, a potential of $-1000 \mathrm{mV}$ was selected to form the deposits.

Table 1S: Elemental composition of CoNi deposits $\left(1.6 \mathrm{C} \mathrm{cm}^{-2}\right)$ on $\mathrm{Si} / \mathrm{Ti}(15 \mathrm{~nm}) / \mathrm{Au}(100$ $\mathrm{nm})$ substrates prepared at different potentials in non-stirring conditions.

\begin{tabular}{c|cc|ccc} 
& & W & W + S & IL/W microemulsion \\
\hline \multirow{2}{*}{$\begin{array}{c}\text { Elemental } \\
\text { Composition / wt. \% }\end{array}$} & $-650 \mathrm{mV}$ & $\mathbf{C o}$ & - & $7 \pm 2$ & $6 \pm 1$ \\
& & $\mathbf{N i}$ & & $93 \pm 2$ & $94 \pm 1$ \\
\hdashline$-900 \mathrm{mV}$ & $\mathbf{C o}$ & $45 \pm 2$ & $34 \pm 2$ & $30 \pm 1$ \\
& & $\mathbf{N i}$ & $55 \pm 2$ & $66 \pm 2$ & $70 \pm 1$ \\
\hdashline & $\mathbf{- 1 0 0 0}$ & $\mathbf{C o}$ & $49 \pm 1$ & $49 \pm 3$ & $49 \pm 3$ \\
& $\mathbf{m V}$ & $\mathbf{N i}$ & $51 \pm 1$ & $51 \pm 3$ & $51 \pm 3$
\end{tabular}



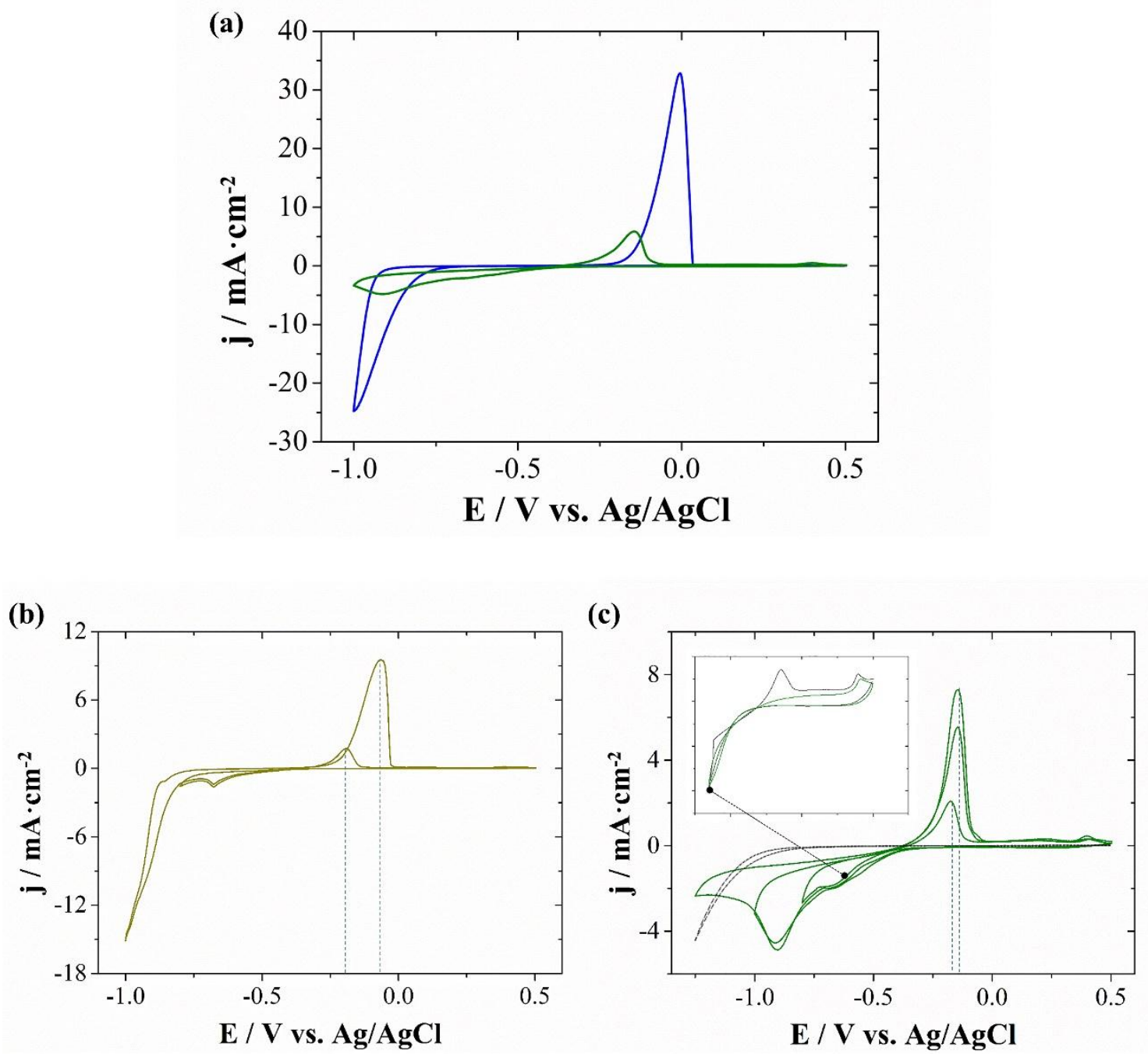

Figure 1S: Cyclic voltammetry under stationary conditions at $50 \mathrm{mV} \mathrm{s}^{-1}$ of (a) aqueous solution (blue line) and IL/W microemulsion (green line); (b) 84.9 wt. \% of aqueous solution +15.1 of Triton X-100; and (c) IL/W microemulsion with (green line) and without (black line) $\mathrm{Co}(\mathrm{II})$ and $\mathrm{Ni}(\mathrm{II})$ species. 


\section{WILEY-VCH}

Conductivity, surface tension and viscosity of various electrochemical media

Table 2S: Conductivity, surface tension and viscosity of the different electrochemical media: aqueous solution $(\mathrm{W})$, aqueous solution + surfactant $(\mathrm{W}+\mathrm{S})$ and IL/W microemulsion.

\begin{tabular}{c|ccc} 
& W & W $+\mathbf{S}$ & IL/W microemulsion \\
\hline Conductivity $/ \mathbf{~ m S ~ c m}^{-1}$ & 104 & 77.7 & 67.9 \\
Surface Tension $/ \mathbf{~ m N ~ m}^{-1}$ & 75 & 32 & 32 \\
Viscosity $/ \mathbf{m P a ~ s}^{-1}$ & 1.43 & 11.1 & 37.5
\end{tabular}




\section{WILEY-VCH}

Cronoamperometric curves, SEM characterization and length distribution of synthesized coni nanorods

(a)
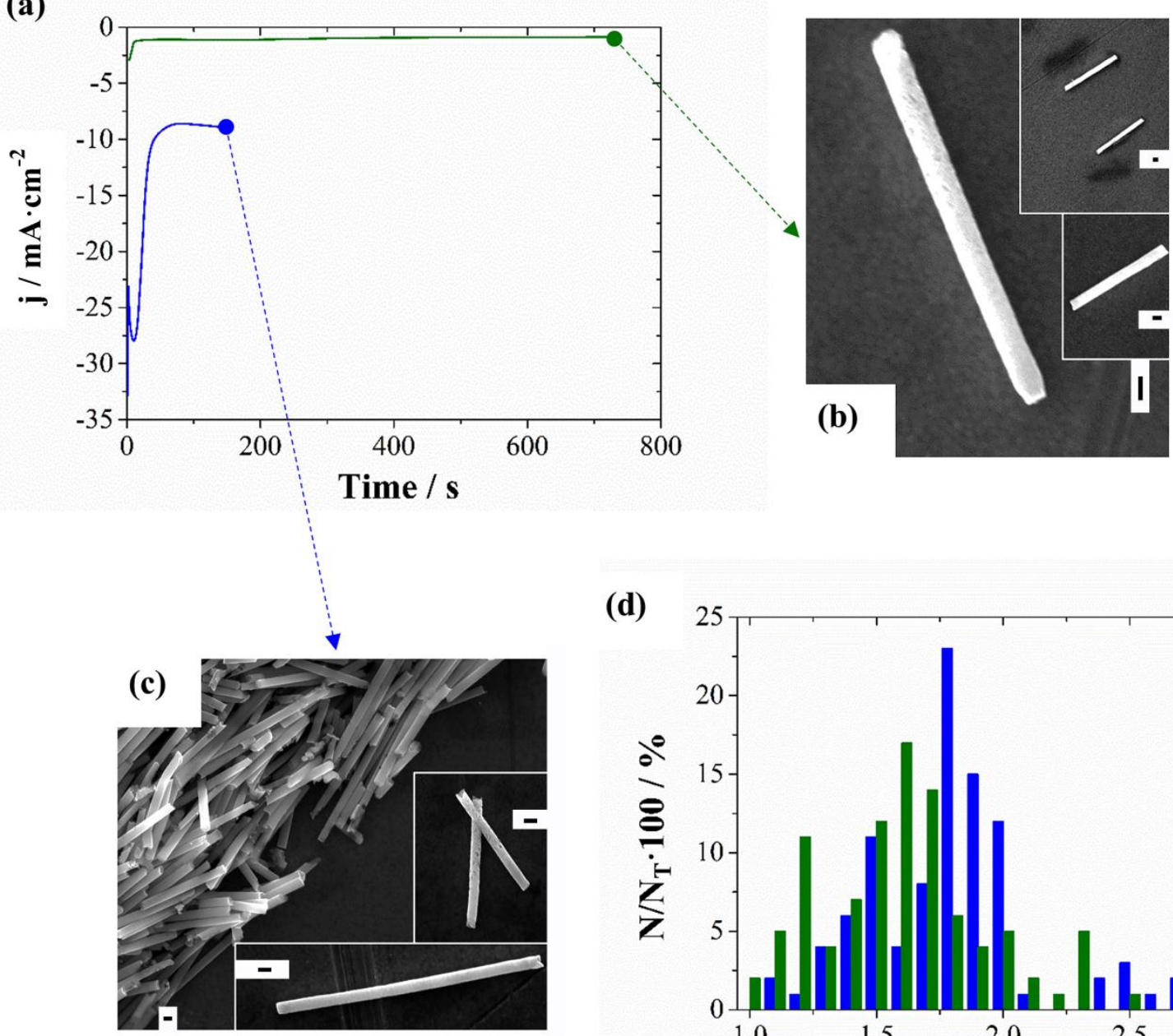

(d)

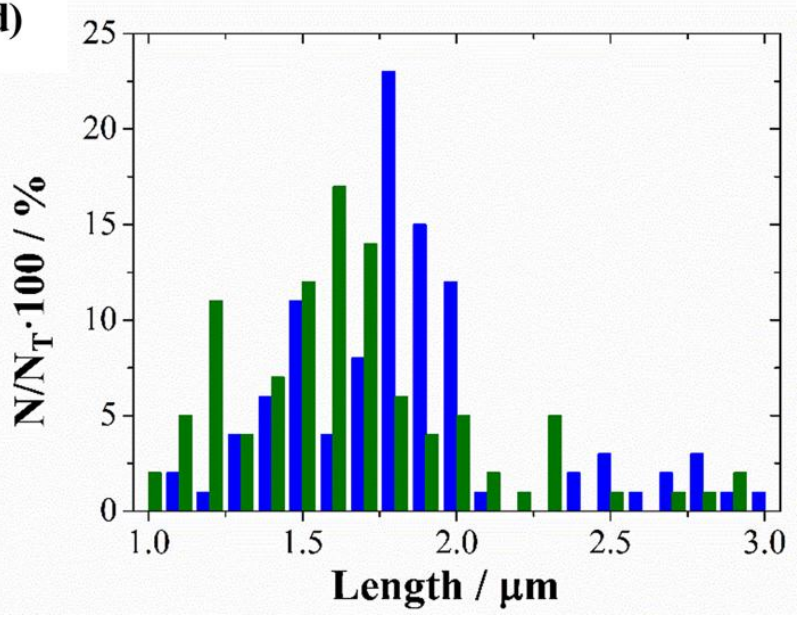

Figure 2S: Chronoamperometric curves (a), SEM images (b, c) and length distribution (d) of CoNi NRs obtained at $-1000 \mathrm{mV}$ on PC membranes at $25^{\circ} \mathrm{C}$ in aqueous solution (blue) and ionic liquid-in-aqueous microemulsion (green). Scale bar: $100 \mathrm{~nm}$. 


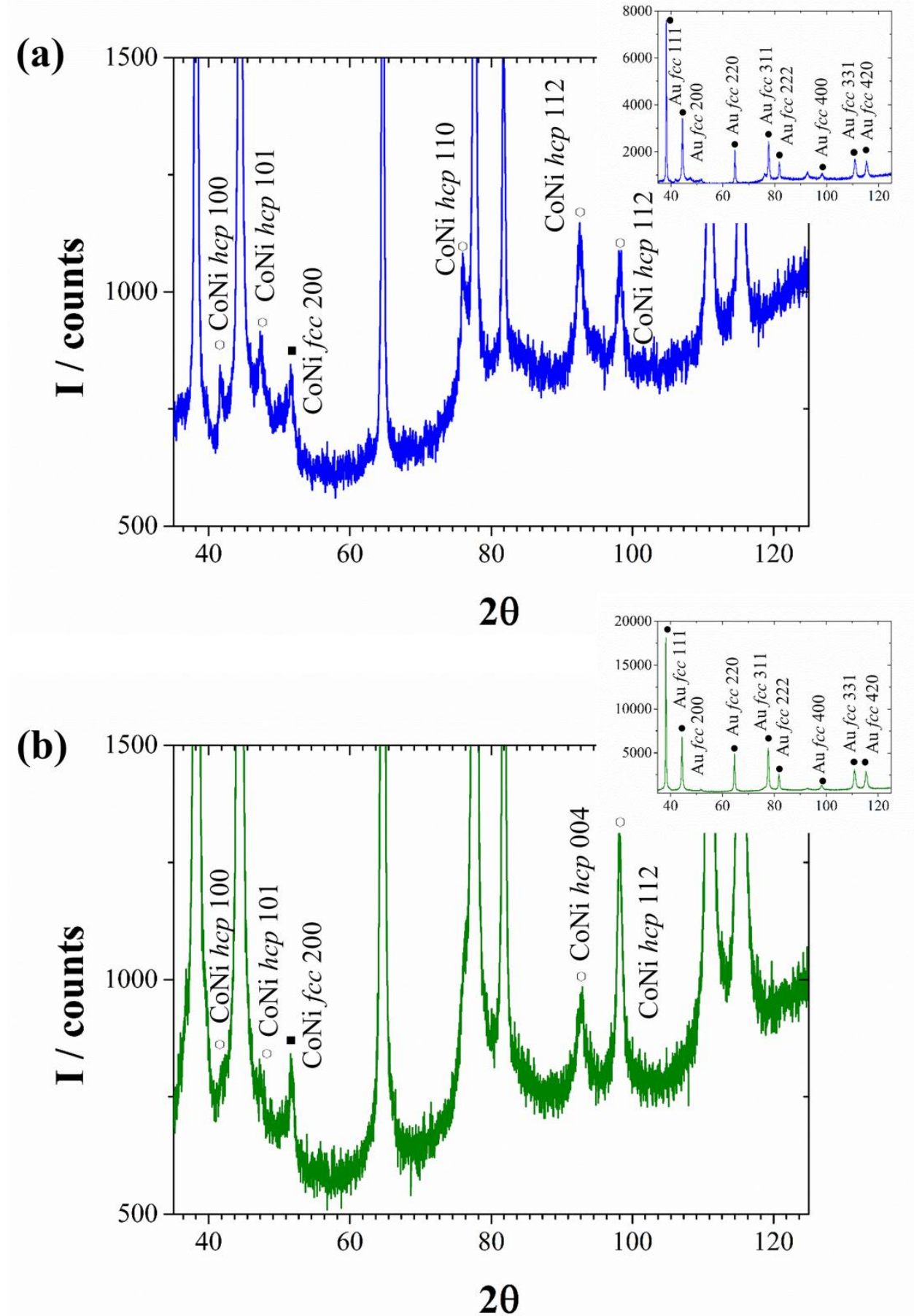

Figure 3S: XRD patterns for (a) compact and (b) mesoporous CoNi@Au nanorods. 


\section{WILEY-VCH}

Selected area electron diffraction patterns and magnetic properties
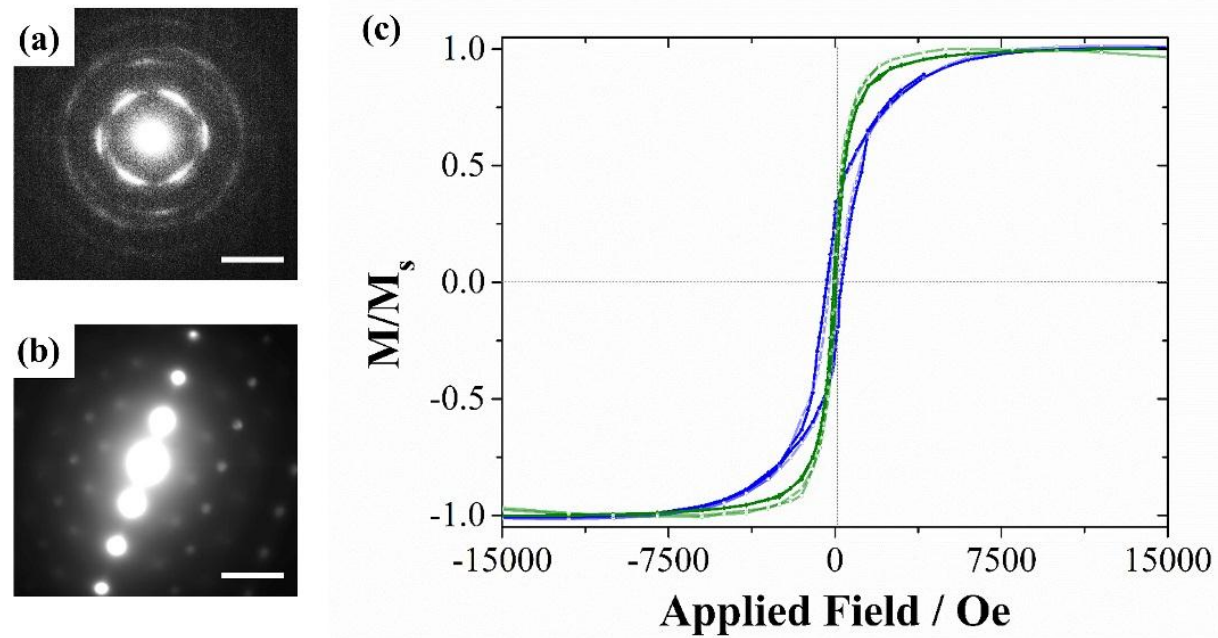

(d)

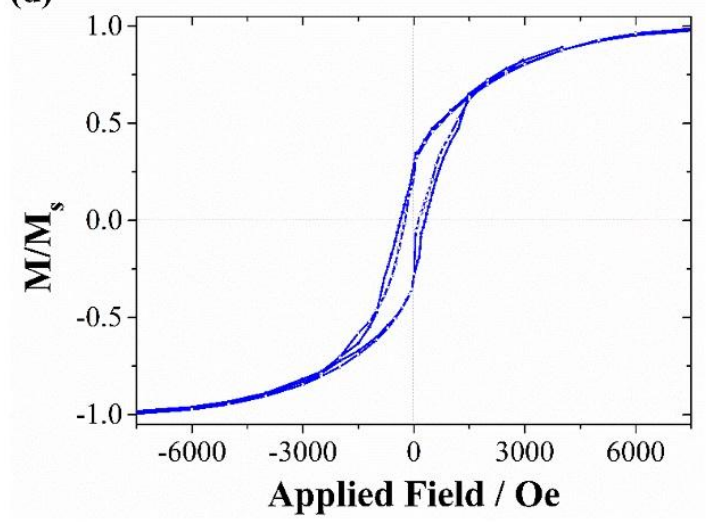

(e)

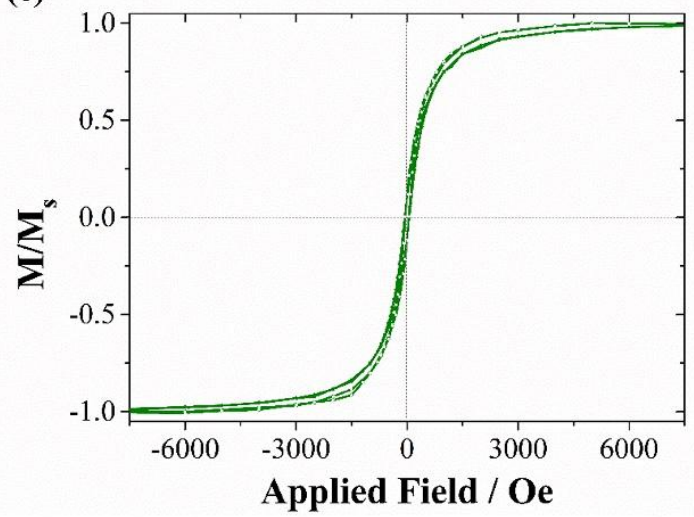

Figure 4S: Representative Selected Area Electron Diffraction (SAED) of compact (a) and mesoporous (b) CoNi@Au NRs. Room-temperature in-plane hysteresis loops of compact CoNi@Au (c and d, continuous blue line) and CoNi@Au-SH-PEG (c and d, dashed blue line) nanorods and mesoporous CoNi@ $\mathrm{Au}$ (c and e, continuous green line) and CoNi@ $\mathrm{Au}-\mathrm{SH}-$ PEG (c and e, dashed green line). Scale bar: $4 \mathrm{~nm}^{-1}$. 


\section{WILEY-VCH}

\section{Cytotoxic activity of CoNi@Au-SH-PEG nanorods}

(a)
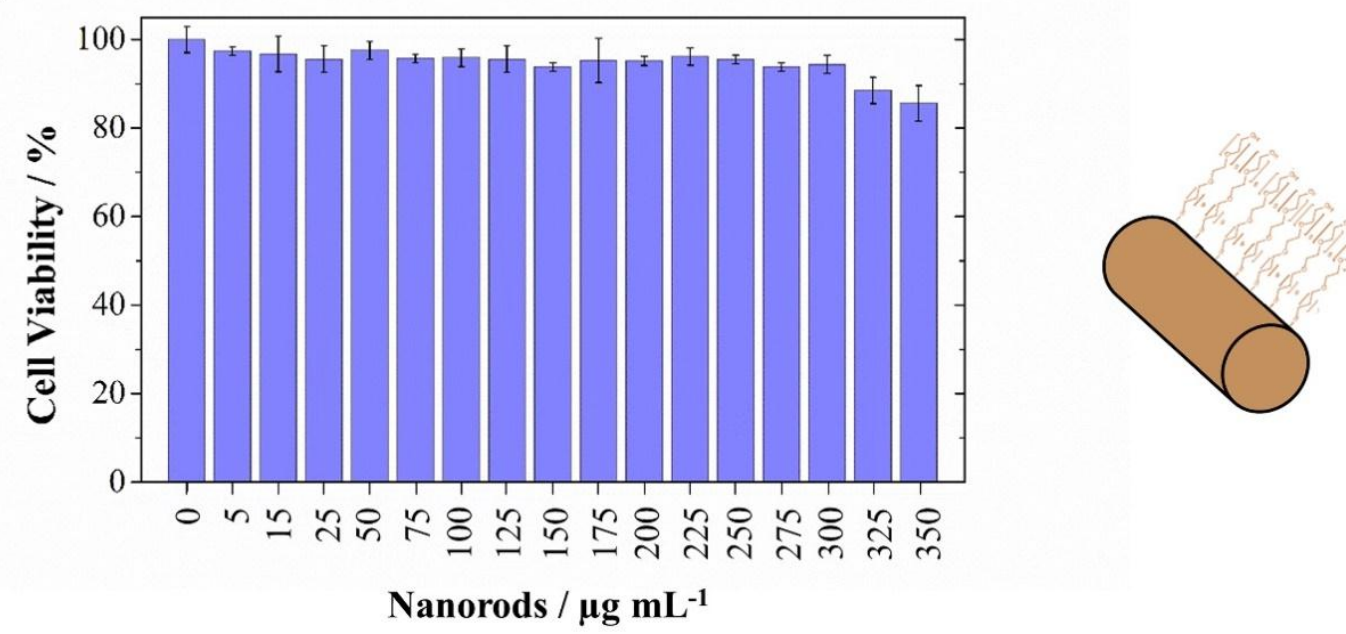

(b)
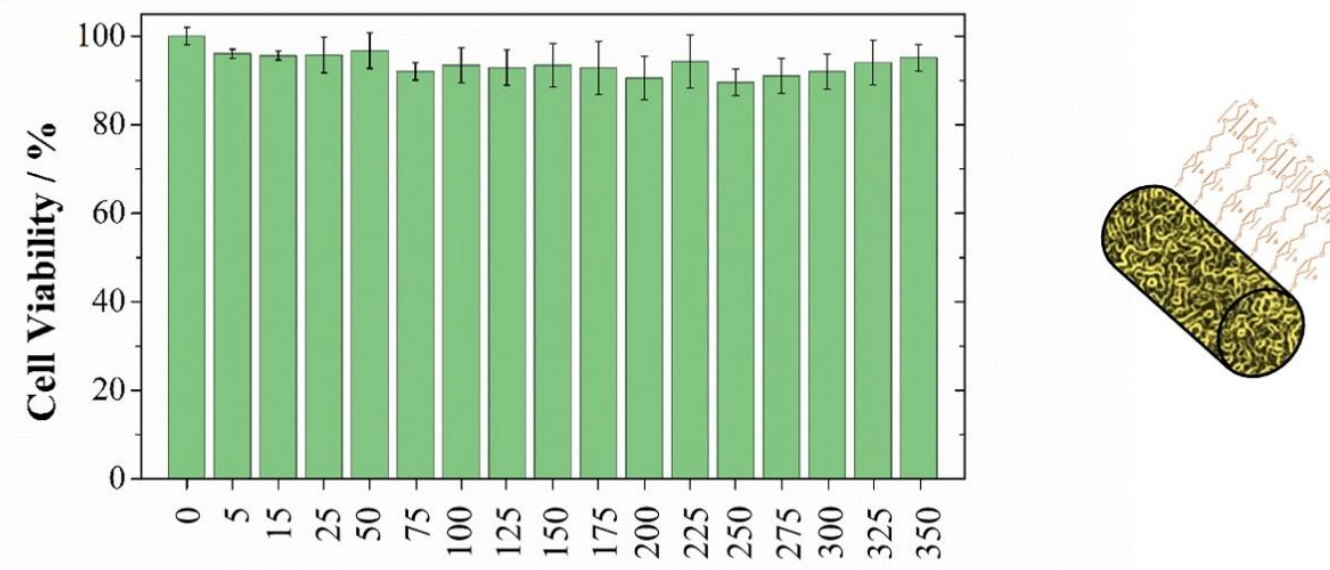

Nanorods / $\mu \mathrm{g} \mathrm{mL}-1$

Figure 5S: HeLa cell viability after incubation for $24 \mathrm{~h}$ with functionalized compact (a) and mesoporous (b) CoNi@Au-SH-PEG nanorods at the amounts indicated in the figure, followed by $24 \mathrm{~h}$ additional incubation with fresh culture medium. 


\section{WILEY-VCH}

Nanorods uptake by HeLa cells

Video 6S. Three-dimensional reconstruction of alive HeLa cells containing compact nanorods in the cytoplasm, demonstrating the internalization of the carriers. See the attached video file for compact NRs.

Video 7S. Three-dimensional reconstruction of alive HeLa cells containing mesoporous nanorods in the cytoplasm, demonstrating the internalization of the carriers. See the attached video file for mesoporous NRs. 


\section{WILEY-VCH}

\section{References}

1. A) N. Zech, E.J. Podlaha, D. Landolt, J. Electrochem. Soc. 1999, 146, 2886; b) E. Gómez, J. Ramírez, E. VallésJ. Appl. Electrochem. 1997, 28, 71. 